\title{
FORME E FUNZIONI DELLO SPAZIO URBANO IN CAMPANIA NELLA TARDA ANTICHITÀ
}

\section{MARCELLO ROTILI}

\author{
UDC: 728.1(1-21)(450.72)"04/05" \\ 902.2 \\ Review \\ Manuscript received: 17. 10. 2016. \\ Revised manuscript accepted: 12. 01. 2017. \\ DOI: 10.1484/J.HAM.5.113758
}

\begin{abstract}
M. Rotili
Dipartimento di Lettere e Beni culturali Università della Campania "Luigi Vanvitelli" Via R. Perla 81055-Santa Maria Capua Vetere
\end{abstract} Caserta, Italia

During the transition time from Late Antiquity to Middle Ages, urban structures in Campania region, in Southern Italy, were involved in a deep transformation process. Many towns were scaled down or even disappeared, due to many factors, namely earthquakes, wars, drop in population and so on. In this context, the Lombard conquest represented the peak of the decay and the consequent dismantling of towns and urban network in the whole Campania. The paper analyzes that process in the light of documents coming from the rich literature, epigraphic sources and, mainly, from archeological campaigns.

Keywords: Late Antiquity, urban structures, Campania.

1. La ricca documentazione letteraria ed epigrafica e le esperienze di archeologia stratigrafica hanno consentito di costatare il ruolo fondamentale che le città con le loro strutture produttive e amministrative ebbero nell'evoluzione socioeconomica della Campania nella tarda antichità rispetto ad altre aree meridionali.

Dopo la lex provinciae di Diocleziano, la Campania presentava un ambito geografico più esteso di quello della regio I augustea. Al territorio della regione fu annesso il Lazio (senza Roma e Ostia amministrate dal praefectus urbi) e alcune città della seconda regione come Benevento e della quarta, fra cui Venafro e Isernia. Fu sottratta, invece, Salerno e assegnata con l'Agro Picentino alla provincia di Lucania e Bruzio.

Dall'età di Costantino in poi la regione fu interessata da una significativa ripresa economica a differenza di quanto succedeva nel resto della penisola italiana. All'epoca, infatti, l'Italia versava in una situazione di decadenza generale determinata dall'imposizione dei tributi (da cui, prima di Diocleziano, la penisola insieme con la Gallia Cisalpina era esentata), dalle lotte civili, dalle prime incursioni delle popolazioni barbariche e dal rinnovarsi della pirateria, pressoché scomparsa dai tempi di Augusto. Il governatore (dal tempo di Diocleziano corrector) che dal 323-324 fu un consolare appartenente all'élite del senato e che negli anni 379-382 e 397-398, sotto gli imperatori Graziano e Onorio, ebbe il titolo di proconsole ${ }^{1}$, risiedeva a Capua, città che recuperò parte dell'antica grandezza. Diocleziano le confermò il rango di colonia attribuendole il suo gentilizio Valerius (la città si chiamò così Concordia Iulia Valeria Felix Capua) e il poeta gallico Decimo Magno Ausonio nel carme Ordo nobilium urbium la elencò fra le dieci maggiori città dell'impero, in ordine d'importanza dopo Treviri e Milano e prima di Aquileia e Arles (comunque dopo Roma, Costantinopoli, Cartagine, Antiochia e Alessandria, considerate alla pari) elogiandone la bellezza, l'opulenza e la fertilità delle campagne ${ }^{2}$.

2. L'importanza della città si evince anche da un altro dato: fu sede anzitempo di un'importante diocesi, il cui primo vescovo Proterio partecipò nel 313 al concilio di Roma. Ad essa l'imperatore Costantino donò metalli preziosi, terre e una basilica Apostolorum. Nel 392 Capua ospitò anche un sinodo di vescovi al quale partecipò Ambrogio di Milano.

La comunità cristiana godeva di una grande autorevolezza e rappresentava la componente predominante della società capuana, che, ciò nonostante, si mostrava molto variegata e viva culturalmente. Dallo studio delle fonti epigrafiche è emerso, infatti, che durante questo periodo nella città erano molto attive anche altre comunità religiose e filosofiche: Ebrei, devoti del culto mitriaco e seguaci del neoplatonismo. Le recenti ricerche archeologiche hanno evidenziato mutamenti radicali nel tessuto urbano tra il IV e il VI secolo d.C. in seguito alla costruzione di ville e abitazioni di grande prestigio e dei primi edifici cristiani. Tali cambiamenti però non interessarono il foro e l'anfiteatro dove è stata registrata «una continuità di uso dovuta al permanere delle funzioni di spazi di rappresentanza e punti di riferimento per il corpo civico. Per il foro la fonte privilegiata di informazioni sono le numerose iscrizioni onorarie che attestano di opere di beneficenza e restauri da parte di governatori, opere che nella seconda metà del IV secolo d.C. potrebbero anche essere state di mera ricollocazione di sculture»3.

${ }^{1}$ A differenza dei correctores e dei consulares subordinati al praefectus ur $b i$, il proconsole rispondeva direttamente all'imperatore se contro le sue sentenze si poteva proporre appello direttamente a quest'ultimo: D. VERA, Commentario storico alle relationes di Quinto Auerelio Simmaco, introduzione, commento, testo, traduzione, appendice su libro X, 1-2, indici, Pisa, 1981, p. 298.

${ }^{2}$ F. CÀSSOLA, La conquista romana. La regione fino al V secolo d. C., in G. PUGLIESE CARRATELLI (ed"s.), Storia e civiltà della Campania, I. L'Evo antico, Napoli, 1991, pp. 138, 147, 148 e la bibliografia citata a note 39, 73. Per il carme Ordo urbium nobilium, v. AUSONIUS, in H.G. EVELYN WHITE (ed.), London-Cambridge (Mass.), 1951, XI, 8, Capua.

${ }^{3}$ F. SIRANO, Capua tardoantica: nuovi dati dall'attività di tutela del patrimonio archeologico, in C. EBANISTA, M. ROTILI (eds.), Territorio, insediamenti e necropoli fra tarda antichità e alto medioevo, Atti dei Convegni internazionale Cimitile-Santa Maria Capua Vetere, 2013-2014, Napoli, 2016, pp. 131-156. 


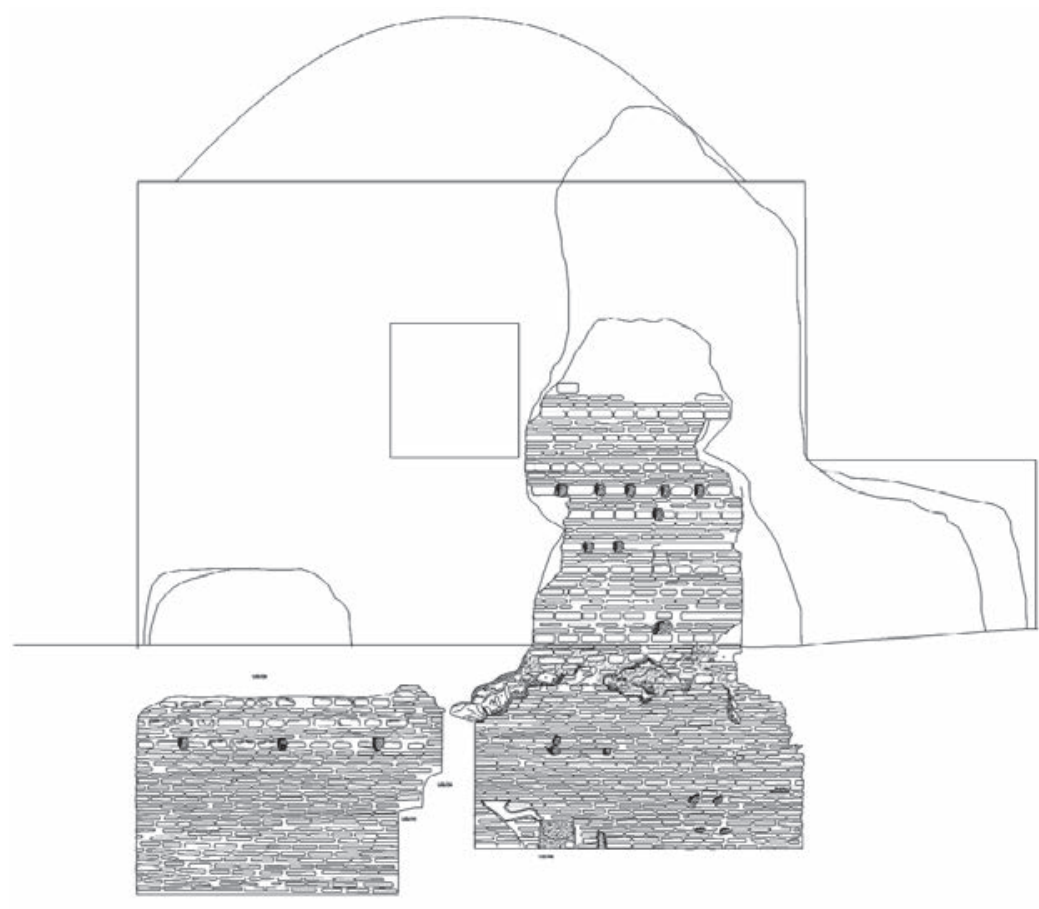

Fig. 1. Area del Catabulum (proprietà Salzillo), prospetto della parete nord dell'edificio, Santa Maria Capua Vetere.

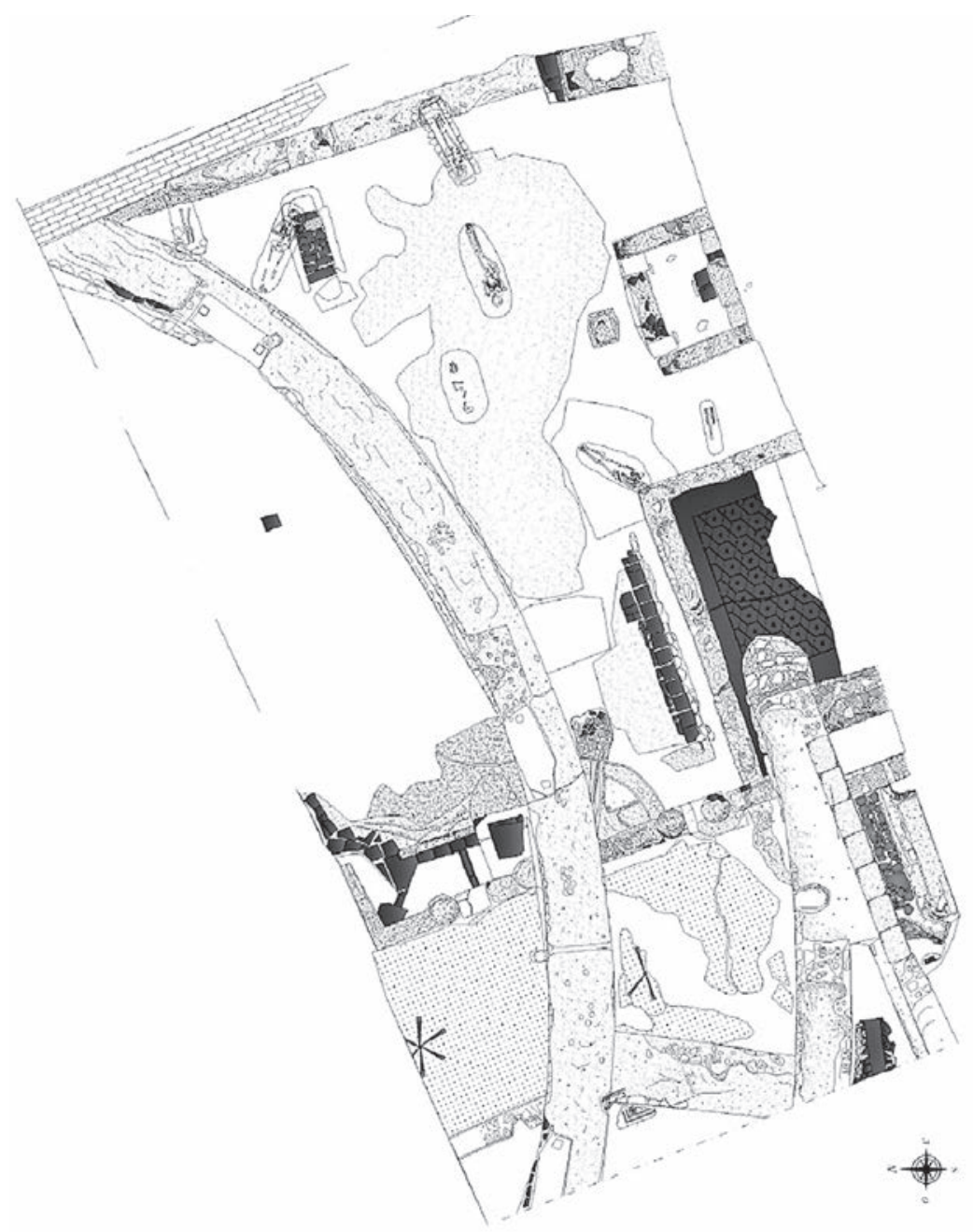

Fig. 2. Area del Catabulum (proprietà Salzillo), planimetria generale degli scavi, Santa Maria Capua Vetere.

${ }^{4}$ Ibidem, pp. 133-149.

${ }^{5}$ A. GIARDINA, Aspetti della burocrazia nel Basso Impero, Roma, 1977, pp. 94-95.
Durante gli scavi in via Cumana, presso la chiesa di S. Paolo apostolo, sono state messe in luce porzioni significative di una villa con una complessa successione stratigrafica che va dal periodo ellenistico sino alla tarda antichità. L'edificio, abbandonato nel VI secolo, in origine era articolato su due porticati di differente grandezza. Gli ambienti che si aprono sul minore, in base della decorazione pittorica, sono attribuibili alla pars dominica. Nel III d.C. questo porticato fu assorbito dalla pars rustica che si sviluppava a nord rispetto ai resti rinvenuti; non è stato purtroppo possibile individuare la completa estensione della pars dominica perché posta al di sotto di edifici contemporanei.

In via Madonna delle Grazie, proprietà Salzillo, è stata integralmente esplorata l'area posta immediatamente a nord del Catabulum, edificio di difficile interpretazione (fig. 1). Durante le indagini archeologiche sono state rinvenute diverse strutture. Le più antiche, di cui non è possibile precisare la funzione, risalgono all'età arcaica. Sono stati individuati i resti di impianti produttivi datati al III secolo a.C. e una domus edificata nel II a.C. e frequentata sino all'avanzato I secolo d.C. Demolita la domus, sulle sue rovine fu depositato un terreno di livellamento sul quale furono realizzati il Catabulum e strutture forse ad esso di poco successive. Si tratta di due muri di fondazione in opera cementizia ad andamento curvilineo concentrico (fig. 2), connessi molto probabilmente ad un'abside di una sala o di un'esedra di un impianto termale. Le strutture, risalenti al II e III secolo d.C., nel VI furono rasate e interrate (l'interro, infatti, ha restituito monete di Valentiniano, frammenti di sigillata africana $C$ e ceramica a bande larghe). Nell'area venne allora impiantato un sepolcreto in relazione con la vicina basilica dei Santi Agata e Stefano.

A nord del decumano, lungo l'attuale via De Gasperi, è stata indagata una superficie estesa più di 900 $\mathrm{m}^{2}$ nella quale è stata individuata una sequenza stratigrafica complessa. Sono state rinvenute strutture di un impianto termale, un cardo e due domus. Quest'ultime furono costruite nel III/II secolo a.C. e unite nel V d.C. in unico complesso abitativo che fu poi abbandonato nel VI. Tra i suoi resti è stato rinvenuto un pavimento a mosaico di IV secolo d.C. con l'emblema decentrato, costituito da una corona vegetale che racchiude un busto maschile (fig. 3). L'uomo è raffigurato con tunica policroma drappeggiata sulla spalla sinistra. Il tipo di corona rimanda a quella trionfale, donata dai generali agli ufficiali meritevoli. Pertanto il ritratto poteva rappresentare un personaggio importante, un cittadino illustre che forse aveva un ruolo eminente nella città di Capua ${ }^{4}$.

3. Le trasformazioni dell'assetto urbano della città rispecchiavano pienamente quel fenomeno di rinnovamento e ripresa generale della provincia campana che, indipendentemente dal rango e dai poteri del governatore (la cui carica spesso fu seconda solo alla preaefectura urbi $i^{5}$ ) conservò grande importanza per l'aristocrazia senatoria le cui vaste proprietà agrarie disseminate in tutto l'impero risultavano direttamente gestibili sole se ubicate in una zona così vicina all'Urbe. 


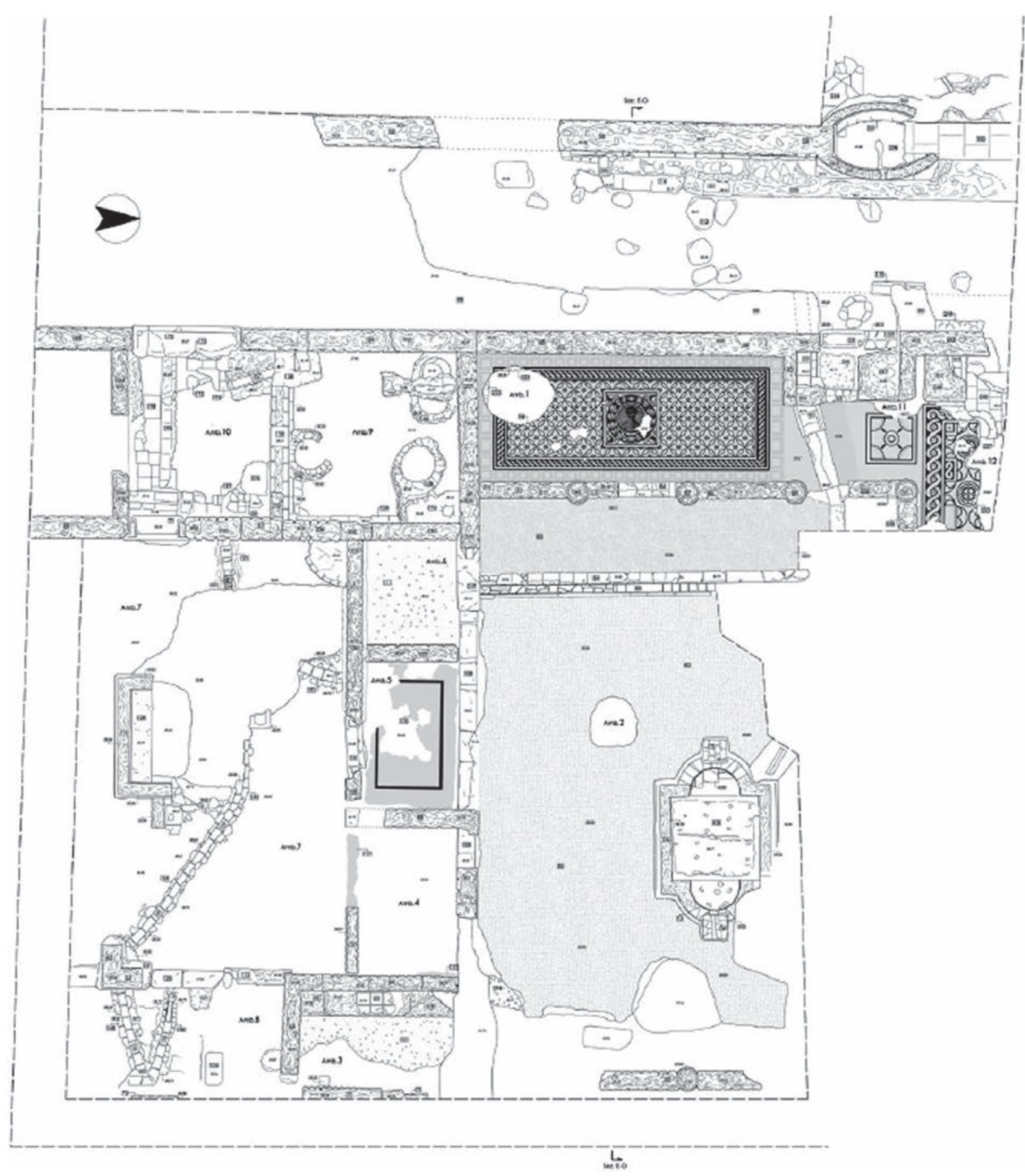

Fig. 3. Via de Gasperi 100 (proprietà COSAMM), planimetria generale degli scavi, Santa Maria Capua Vetere (Caserta).

Pertanto la Campania fu assiduamente frequentata dagli aristocratici, che durante questi 'viaggi di affari' presero a frequentare nuovamente luoghi di villeggiatura e bagni termali che avevano goduto in passato di una grande fama. La loro presenza attirò anche visitatori meno blasonati, come quei terrae filii (o 'illustri sconosciuti') che Simmaco volle evitare nel 375 lasciando Baia, dove al momento si trovava, per rifugiarsi prima a Napoli, poi a Benevento ${ }^{6}$.

A testimonianza di questo flusso 'turistico' sono state ritrovate in diverse località (Mèrida, Odemira, Roma, Ampurias, Populonia, Ostia, Colonia e recentemente Astorga) fiaschette di vetro prodotte nell'area napoletana tra la fine del III e il IV secolo d. C., veri e propri souvenir, su cui sono riprodotte le vedute della città di Puteoli o di Baia (figg. 4, 7).
Le raffigurazioni, tutte piuttosto simili, realizzate secondo un modo di rappresentare convenzionale, compendiario e schematico, mostrano impianti portuali ad arcate, templi ornati all'interno da statue colossali, archi trionfali con quadrighe, impianti termali, vasche per l'allevamento delle ostriche e anfiteatri e sono accompagnate da iscrizioni esplicative (fig. 7). In esse sono, comunque, individuabili veri riferimenti topografici. In riferimento a Baia Gianfrotta sostiene che «conformemente al criterio riscontrato per le bottiglie della serie puteolana, i monumenti raffigurati risultano in relazione topografica coerente e compongono il grandioso nucleo unitario del palatium di Baia, le cui monumentali architetture rimasero tali anche dopo il trasferimento degli imperatori a Costantinopoli. La sua rappresentazione sulle

${ }_{6}^{6}$ SYMMACHI Epistulae, I 3, 3 e 5, in Q. AURELI SYMMACHI quae supersunt, O. SEEK (ed.), in M.G.H., Auctores antiquissimi, VI, Berlin, 1883, n. ed. 1961, pp. 1-278, a pp. 4-5. 


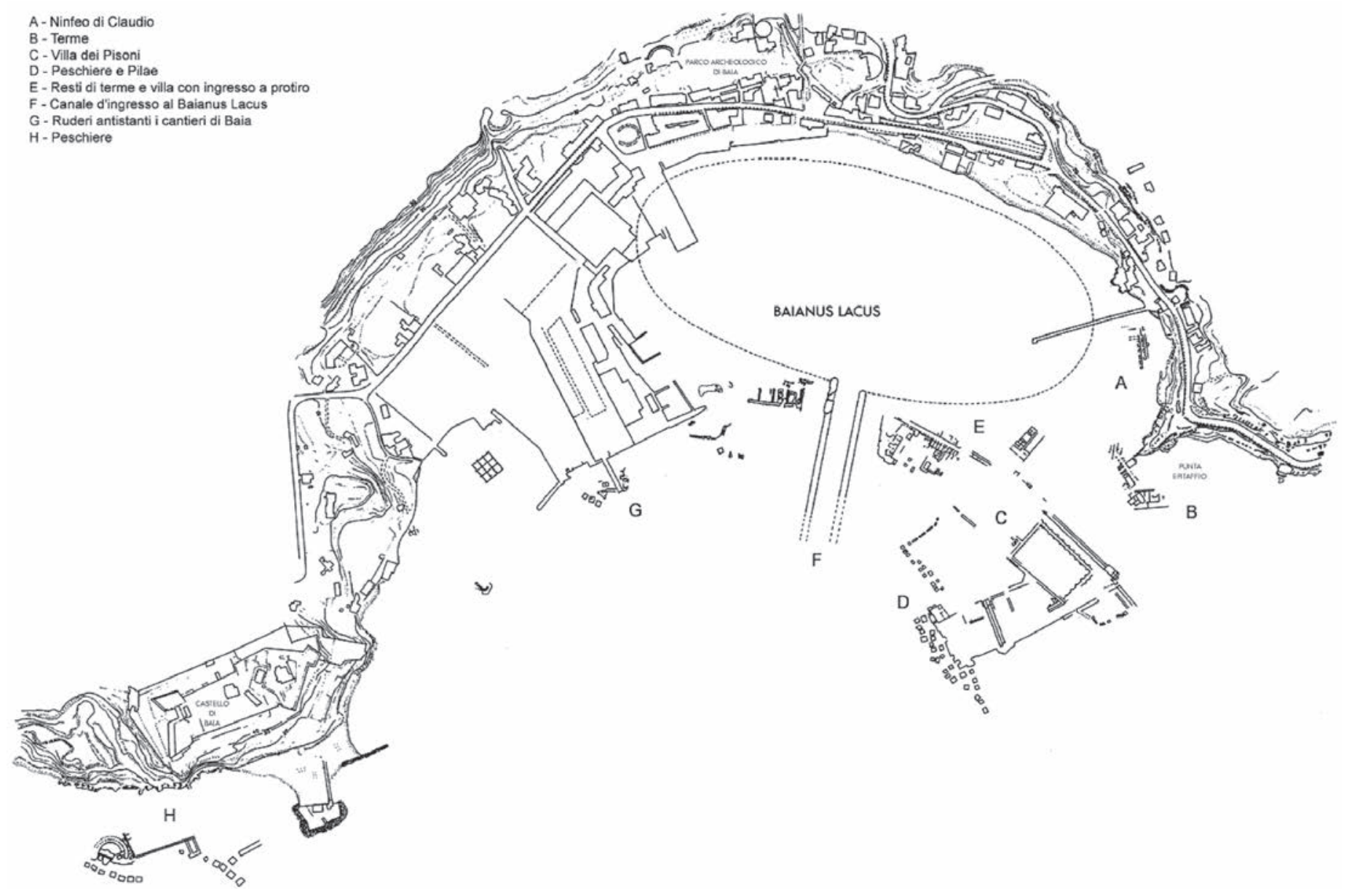

Fig. 5. Baia, planimetria generale.

bottiglie continuava a mostrare il diretto legame al potere imperiale di quei luoghi celebri, di vacanze e di frequentazioni altolocate. Il palatium imperiale accorpava quasi l'intera Baia, dislocato in vari settori lungo tutto il bordo del cratere baiano, comprendendo l'attuale parco archeologico e le terme» ${ }^{7}$.

La città di Baia (fig. 5) godè di un notevole prestigio come località di villeggiatura fino al VI secolo, anche se già sul finire del IV si manifestarono i primi segnali del lento movimento discendente (bradisismo) che portò alla progressiva scomparsa della fascia costiera trascinando sott'acqua ville, residenze e complessi termali. Emblematico è il caso
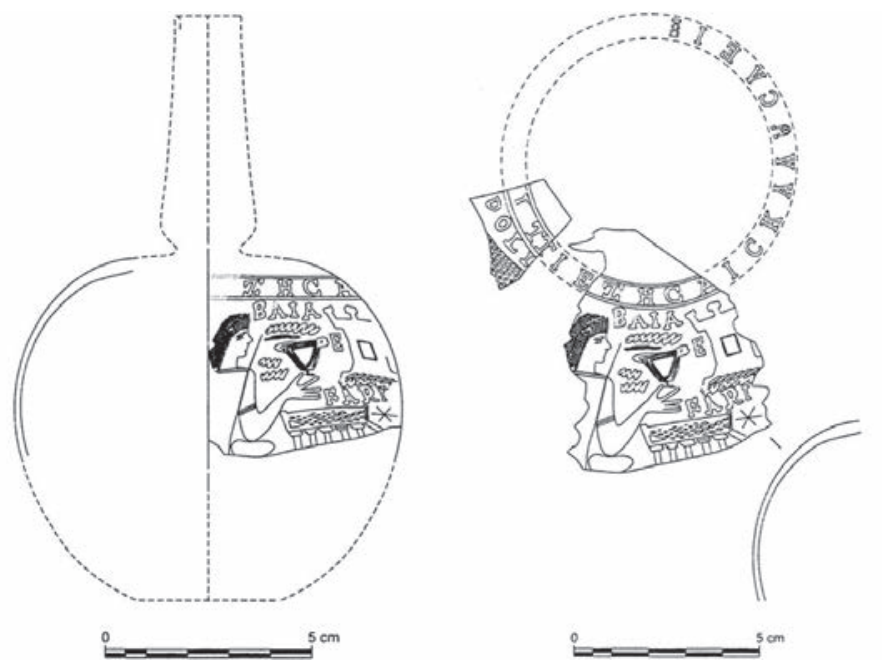

Fig. 4. Frammenti di ampolle, raffiguranti Baia, rinvenute ad Astorga (Spagna). del ninfeo della residenza dell'imperatore Claudio (fig. 6). Risalente al I secolo, fu frequentato fino al IV, quando furono

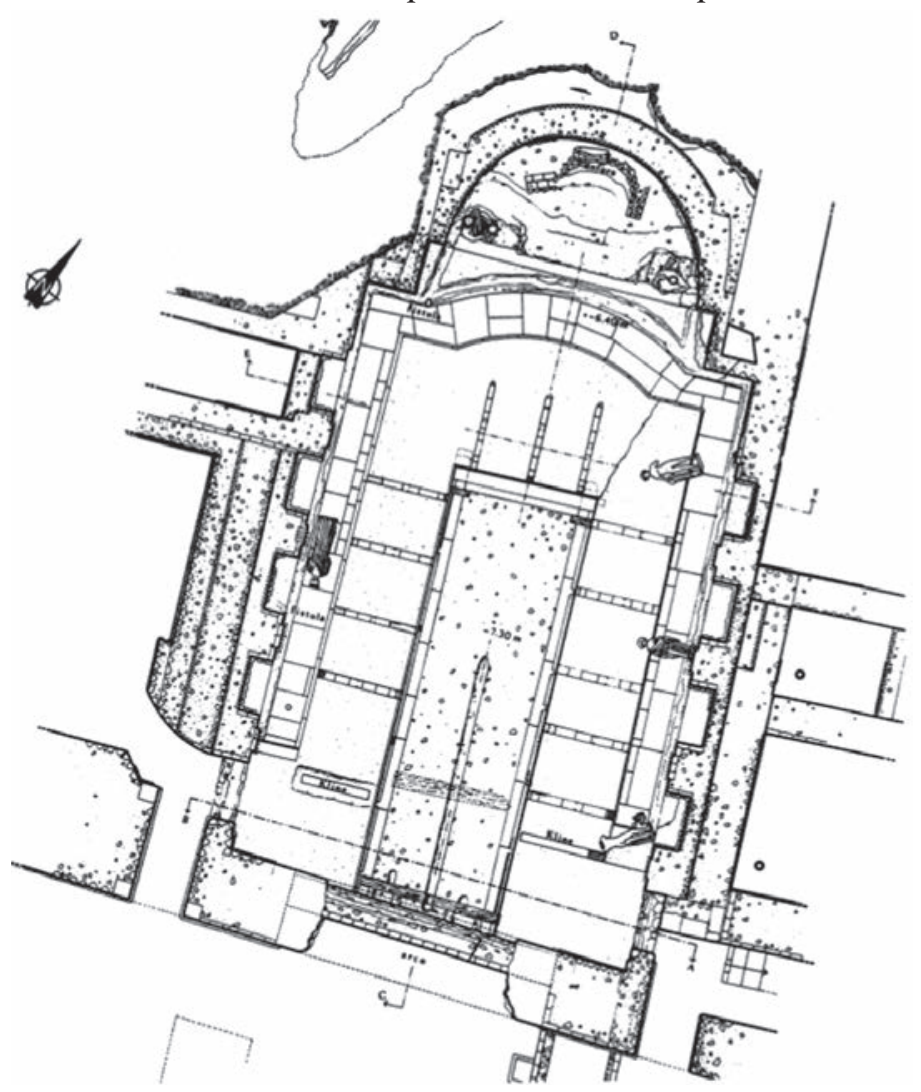

Fig. 6. Pianta del ninfeo di Claudio, Baia.

${ }_{7}$ P. A. GIANFROTTA, La topografia sulle bottiglie di Baia, in Rivista di Archeologia, XXXV-2011, Roma, 2012, pp. 13-40. 
realizzati gli ultimi restauri e rifacimenti. Poi, a causa del progressivo abbassamento bradisismico, venne usato come butto. I numerosi reperti rinvenuti hanno consentito di datare il processo di stratificazione del riempimento, oltre ad aver dato notevoli informazioni sulle produzioni locali dell'epoca. Il riempimento, infatti, venne costituito in varie fasi; ad ogni diminuzione della quota dei locali, con conseguente allagamento, venivano gettati detriti per creare un nuovo piano di calpestio che ne consentisse ancora l'uso. Il ninfeo venne definitivamente abbandonato all'incirca nel V secolo, quando il crollo delle parti alte lo rese inagibile ${ }^{8}$.

4. Nonostante le amplificazioni retoriche proprie dei documenti ufficiali, le informazioni sul «risveglio della Campania» in età costantiniana (per usare le parole di Ettore Lepore9) indicano che la situazione precedente (dai conflitti interni del III secolo fino alla tetrarchia) era stata disastrosa. Prima che Costantino facesse restaurare l'acquedotto puteolano «fatiscente per l'antichità e la lunga incuria $»^{10}$, un anonimo puteolano se n'era occupato «pecunia sua», ma è da presumere che, nella sua qualità di "curator aquae Augustae»" avesse restaurato solo quel ramo dell'aqua Augusta che riforniva la propria città, il che dimostra l'assenteismo delle autorità. Ad Avella ingenti lavori di ricostruzione furono promossi dal senatore Barbaro Pompeiano ${ }^{12}$, consolare della Campania nel 333, che ebbe cura di far estrarre le pietre dalle cave, non dai monumenti abbandonati e in rovina secondo una pratica che evidentemente era già consueta. Il ritorno ad una vita ordinata risultò benefico per i commerci di Pozzuoli ove per tutto il IV secolo fiorì l'industria del vetro ${ }^{13}$, ove il macellum danneggiato da una mareggiata fu restaurato al tempo di Teodosio dal governatore della provincia ${ }^{14} \mathrm{e}$ dove l'esistenza del Procurator portus Puteolanorum dimostra che in età costantiniana il porto era ancora attivo e tutelato dalle istituzioni15: si sa del resto che nel I secolo Pozzuoli era stato il maggior centro commerciale della Campania e di tutta la costa tirrenica, essendo l'approdo per la flotta che trasportava dall'Egitto il grano destinato a Roma e che le lucrose attività legate anche alla presenza di mercanti di Tiro e Beirut era stata ridimensionata dall'implementazione del porto di Ostia voluta da Traiano agli inizi del II secolo per far giungere alla foce del Tevere le merci dirette alla

Fig. 7. Raffigurazioni di Baia su frammenti di bottiglie.

capitale diminuendo così il costo del trasporto; ciò aveva ridimensionato il ruolo dell'approdo puteolano che tuttavia era rimasto il porto della Campania e del suo entroterra, porto nel quale nel II e III secolo sono ancora documentati mercanti iberici e fenici sebbene questi ultimi si fossero trasferiti in gran parte a Roma in rapporto allo sviluppo del porto di Ostia che peraltro dev'essere entrato in attività forse già con Antonino Pio o Marco Aurelio, quindi ben prima del tempo di Commodo (circa 70 anni dopo Traiano), allorché sono attestati per la prima volta gli equipaggi della flotta di Alessandria impegnati nel trasporto del grano ${ }^{16}$.

A conferma dei dati storici sull'evoluzione sull'importanza di Pozzuoli durante l'età imperiale e la tarda antichità giungono anche i risultati delle indagini archeologiche condotte dal 1993 al 2011 per conto della Soprintendenza per i Beni Archeologici di Napoli e Caserta come preliminari all'intervento, promosso dalla Regione Campania, di

\footnotetext{
${ }^{8}$ A. BENNINI, Storia, archeologia e tutela dei beni archeologici sommersi: l'esempio dei Campi Flegrei, in M. GIACOBELLI (ed.), Lezioni Fabio Faccenna II. Conferenze di archeologia subacquea (III-V ciclo), Bari, 2004, pp. 34-43.

9 E. LEPORE, La vita politica e sociale, in Storia di Napoli, I, Cava de' Tirreni, 1967, p. 263.

${ }^{10}$ I. SGOBBO, Iscrizione del 324, in Notizie degli Scavi di Antichità, LXIII, 1938, pp. 75-97.

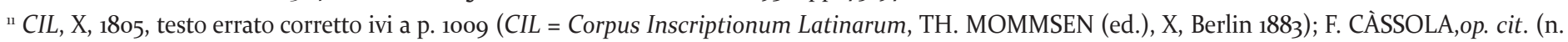
2), pp. 103-150.

${ }^{12}$ CIL, X, 1199, op. cit (n. 11); iscrizione in suo onore a Preneste su lastra di reimpiego, cfr. CIL, XIV, 2919, op. cit (n. 11).

${ }^{13}$ È testimoniata dalla produzione delle fiasche globulari già citate precedentemente in relazione alla città di Baia.

${ }^{14}$ CIL, X, 1690-1692, op. cit (n. 11).

${ }^{15}$ J. H. D’ARMS, Commercial and social Standing in Ancient Rome, Cambridge (Mass.), 1981, p. 124, nota 9.

${ }^{16}$ Cfr. F. CÀSSOLA, op. cit (n. 2), pp. 137-138. Sui mercanti fenici CIL, X, 1634; sulla presenza degli equipaggi di Alessandria ad Ostia G. SACCO, Iscrizioni greche d'Italia: Porto, Roma,1984, n. 2.
} 
restauro e valorizzazione dell'antico centro storico di Pozzuoli. È stata indagato principalmente il Rione Terra, dov'era impiantata la città antica, le cui stratigrafie testimoniano una lunga e intensa frequentazione che va dall'epoca repubblicana sino al IV-V secolo. Di particolare interesse è stato il rinvenimento di un foro transitorio, obliterato da costruzioni della metà del secolo scorso. Su di esso si affacciavano gli edifici pubblici, tabernae e opifici in cui sono attestate varie fasi edilizie databili dall'epoca repubblicana sino a quella tardoantica. Anche lo scavo dello stadio, costruito da Antonino Pio in memoria di Adriano, ha confermato l'importanza e la continuità d'insediamento dell'area. Nella struttura sono stati evidenziati, infatti, numerosi interventi edilizi susseguitisi nel tempo, realizzati con diverse tecniche costruttive (opus latericium, mixtum e vittatum). Lo stadio perse la sua funzione in epoca tardo-antica e ne venne obliterata la pista. Sull'interro furono realizzati un portico a pilastri e un edificio a pianta poliabsidata, a loro volta celati dai materiali che avrebbero consentito la successiva destinazione agricola della cavea ${ }^{17}$.

5. Fra IV e V secolo nelle città campane svolse nuovamente un ruolo rilevante l'evergetismo, ma raramente i benefattori furono cittadini facoltosi che avevano le disponibilità economiche per spendere per la propria comunità, a causa delle condizioni critiche in cui si trovavano le élites municipali. L'obbligatorietà della carica curiale (un tempo méta ambita del cursus honorum) implicava per chi la ricoprisse il dovere di mantenere a proprie spese le opere pubbliche, ma questa condizione induceva a far fronte alle esigenze minime, come garantire il funzionamento di terme e mercato. Spesso l'evergete era un esponente della classe senatoria che assumeva titolo e impegni di patronato perché legato alla città da interessi economici e dall'origine della sua famiglia: egli poteva essere patronus originalis (cioè per tradizione familiare) o patronus ab atavis (dai più remoti antenati). Capua conferì questa qualifica a Claudio Petronio Probo, console nel 371 e prefetto del pretorio per l'Italia, la Gallia, l'́llirico e l'Africa ${ }^{18}$; ad Anicio Paolino, proconsole della Campania nel 378-379 quindi praefectus urbi; a Ponzio Proserio Paolino (probabilmente un nipote di S. Paolino di Nola) consolare della provincia nel 409 che fu anche patrono di Pozzuoli' ${ }^{19}$. Napoli contava sul patronato di Ni- comaco Flaviano ${ }^{20}$, genero di Simmaco, che fu governatore della Campania in data sconosciuta e di Anicio Auchenio Basso $^{21}$, un beneventano che beneficiò anche la sua città e che, dopo essere stato proconsole fra il 379 e il 382, divenne praefectus urbi. A Benevento troviamo Valerio Publicola ${ }^{22}$ figlio di Melania senior e padre di Melania iunior ben note per l'attività benefica e per aver contribuito alla fondazione di molti monasteri. Tranne Nicomaco Flaviano i personaggi citati erano tutti cristiani; nonostante ciò, forza e incidenza del paganesimo sono documentati dall'incisione a Capua nel 387 di un feriale ${ }^{23}$ che indica numerose cerimonie pagane celebrate in Campania (nel IV si rileva una rinascita del culto della Sibilla e dell'Apollo di Cuma) e quanto Simmaco dice degli ottimati di Benevento che finanziarono la ricostruzione dopo il terremoto del 346: «amantissimi litterarum», «deos pars magna veneratur» ${ }^{24}$, erano cioè in maggior parte pagani.

6. L'obbligo imposto alle province dai successori di Diocleziano di rifornire Roma di derrate che l'annona distribuiva agli iscritti nelle sue liste gratuitamente o a prezzo politico comportò per la Campania la fornitura di vino e di carne di maiale. Almeno fino al VII secolo è documentata a Roma un'anfora globulare di produzione campana impiegata per il trasporto del vino, il che significa che le esportazioni durarono ben oltre la fine dell'impero, al riguardo anzi la mancanza di anfore, peraltro prodotte nella baia di Napoli anche nell'VIII e IX, è poco indicativa perché per il trasporto del vino dopo il IX secolo furono impiegate botti ${ }^{25}$; è tuttavia improbabile che l'arca vinaria della capitale curasse la distribuzione di vini pregiati come il Gaurano e il Falerno ${ }^{26}$ ancora apprezzati a fine IV ed evidentemente riservati al mercato libero.

Oltre all'allevamento suino, che quindi doveva essere tanto diffuso in Campania da poterne consentire l'esportazione delle carne, una legge del 364 d.C. menziona anche allevamenti di pecore e bovini ${ }^{27}$. Dal 352 la regione dovette fornire anche grano. Infatti, nell'opera Expositio totius mundi, un resoconto di un autore anonimo che descrive i domini imperiali del IV secolo, la Campania è chiamata cellarium di Roma ${ }^{28}$. Quest'obbligo riguardò varie città fra cui Capua. Un dato interessante è quello fornito da Simmaco che nel raccontare una lunga vicenda riguardante l'approv-

\footnotetext{
${ }^{17}$ M.L. NAVA, Ricerche e scoperte archeologiche per la tutela e la valorizzazione del patrimonio archeologico nel territorio di Napoli e Caserta, in A. CORALLINI (ed.), Vesuviana, Archeologie a confronto. Atti del Convegno Internazionale (Bologna 14-16 gennaio 2008), Bologna, 2009, pp. 67-84.

${ }^{18}$ F. CÀSSOLA, op. cit (n. 2), pp. 141, 149, nota 99.

${ }_{19}$ CIL, X, 1702, op. cit (n. 11).

${ }^{20}$ ILS, 8985 (ILS = Inscriptiones Latinae selectae, H. DESSAU (ed.), Berlin, 1892-1916, new ed. Chicago, 1979).

${ }^{21}$ CIL, IX, 1568-1569, op. cit (n. 11).

${ }^{22}$ Ibidem, IX, 1591.

${ }^{23}$ Ibidem, X, 3792.

${ }^{24}$ SYMMACHI Epistulae, I 3, 4, op. cit. (n. 6), pp.4-5.

${ }^{25}$ P. ARTHUR, Naples. From Roman Town to City-State (Archaeological Monographs of the British School at Rome, 12), Hertford-London-Rome, 2002, pp. 112-113.

${ }^{26}$ Il Falerno, in particolare, era molto gradito ai tempi di Diocleziano tanto che fu menzionato con una nota di buona valutazione nel calmiere dei prezzi imposto dall'imperatore: Falerini Italici (sextarium) unum (denarios) triginta, cfr. L. CRIMACO, F. SOGLIANI, Indagini preliminari sull'insediamento fortificato di Monte Petrino (Mondragone - Caserta). Prime note per la ricostruzione delle strutture insediative tra tardoantico e medioevo nella Campania settentrionale, in G.P. BROGIOLO (ed.), II Convegno Nazionale di Archeologia Medievale (Brescia sett.-ott. 20oo), Firenze, 2000, pp. 199-208.

${ }_{27}$ C. TH., IX 30, 2 (C. TH.= TH. MOMMSEN, P. M. MEYER (ed.), Theodosiani libri XVI cum constitutionibus Sirmondianis et leges Novellae ad Theodosianum pertinentes, Berlino, Weidemann, 1905); L. CRIMACO, F. SOGLIANI, op. cit. (n. 26), pp. 199-201.

${ }^{28}$ Exp. Tot. Mundi, 55 (Expositio totius mundi et gentium = Descrizione del mondo e delle sue genti. Anonimo del IV secolo; introduzione e note di U. LIVADIOTTI; traduzione di M. DI BRANCO, Salerno, 2005); L. CRIMACO, F. SOGLIANI, op. cit. (n. 26), pp. 199-201.
} 
vigionamento cerealicolo di Pozzuoli e Terracina ${ }^{29}$ scrive che l'imperatore Graziano condonò, su richiesta di Capua, il versamento di grano a favore di Roma e che quindi vennero restituiti alla città 38.0oo modii di grano. Emerge, dunque, che Capua ancora nel IV secolo aveva una produzione cerealicola (concentrata soprattutto nella piana del Volturno) tale da porla in condizione di fornire la stessa Roma.

$\grave{E}$ documentato, invece, che la vicina Napoli beneficiò delle importazioni di frumento e olio dall'Africa e dalla Sicilia sino agli inizi del VI secolo, mentre dopo il VII sarebbe stata la Liburia a fornire verosimilmente la maggior parte del grano alla città ${ }^{\circ}$ che nell'alto medioevo viene sempre più configurandosi come vera e propria città-stato in grado di rifornire l'entroterra longobardizzato ${ }^{31}$.

7. Nella seconda metà del IV secolo l'eccessiva pressione fiscale aggravata dalle contribuzioni annonarie indusse molti proprietari ad abbandonare le terre meno redditizie e, poiché la principale imposta fondiaria era commisurata alla superficie e alla produttività presunta della terra (indipendentemente dall'utile effettivamente realizzato), i proprietari terrieri della Campania chiesero al giovane imperatore Onorio, appena succeduto al padre Teodosio, uno sgravio fiscale; Simmaco, probabilmente interessato all'esonero, presentò al magister epistularum di Onorio, Minervio, una delegazione campana portatrice di istanze a suo parere plausibili di cui l'epistula ${ }^{32}$ non fornisce dettagli: e così un rescritto imperiale dispose nel $395^{33}$ la cancellazione dai ruoli dell'imposta fondiaria di 528.042 iugeri, più di 133 .00o ettari, e la distruzione dei relativi documenti catastali34. L'abbandono di cui ciò sembra indizio35, appare correlato anche a fattori di recessione propri della società di IV-V secolo come la contrazione demografica e lo spopolamento di alcune aree.

8. Nonostante la ripresa economica durante l'impero di Costantino, il terremoto del $346^{36}$ che devastò moltissime civitates Campaniae fra le quali Beneventum, Abellinum e Compsa aveva contribuito a porre le premesse del declino che, agli inizi del V secolo37, avrebbe trovato una delle sue ragioni nella decadenza di Roma, nel conseguente mancato sbocco di mercato dell'agricoltura campana e nell'aggravamento delle condizioni generali: la Campania non era stata mai investita da un'invasione perché gli Iutungi che si erano spinti più a sud di altre popolazioni germaniche erano stati fermati a Fano da Aureliano (271) ma nel 410 i Visigoti di Alarico, dopo aver saccheggiato Roma, comportandosi peraltro con moderazione perché volevano perseguire un accordo con l'imperatore, scesero in Campania ove occuparono Nola tanto che Paolino di Bordeaux, esponente di una ricchissima famiglia, verosimilmente pagò il riscatto per liberare se stesso e i Nolani. La gravità della situazione è indicata da due provvedimenti di Onorio che nel 413 ridusse ad 1/5, per 5 anni, le imposte sulla Campania e che alla scadenza, nel 418, fu costretto ad abbassarle ulteriormente portandole ad $1 / 9^{38}$. La situazione sarebbe stata peraltro aggravata dai Vandali di Geiserico che saccheggiarono Roma per 14 giorni nel 455 portandosi quindi in Campania ove investirono numerose città fra cui Capua e Nola ${ }^{39}$. Divenuti un pericolo gravissimo da quando, passati dalla Spagna in Africa nel 429 e conquistata Cartagine nel 439, avevano avviato una politica di scorrerie e attacchi contro le coste italiane, erano stati la causa del rafforzamento di Napoli che, proprio perché fortificata e protetta dalle loro incursioni, nella seconda metà del V avrebbe acquistato il ruolo di principale porto della Campania in sostituzione di Pozzuoli: un'iscrizione databile fra 425 e 450 per la presenza dei nomi di Valentiniano III (425-455) e Teodosio II (imperatore d'Oriente, 408-450) informa che Valentiniano fece restaurare mura e torri di Napoli ${ }^{40}$ accrescendo le capacità difensive dei quartieri occidentali e meridionali. Nella circostanza fu trasformata in fortezza anche la villa di Lucullo che comprendeva un buon tratto della costa lungo lo scoglio di Castel dell'Ovo ma il Castrum Lucullanum o Castellum Lucullanum (che viene ubicato anche sulla collina di Pizzofalcone) pare fosse ancora più esteso dell'impianto di età classica ${ }^{41}$ : in esso com'è noto sarebbe stato relegato nel 476 Romolo Augustolo, l'ultimo imperatore deposto da Odoacre. Ai Vandali non riuscì di espugnare Napoli, comunque ne devastarono il territorio rimanendo un pericolo gravissimo come conferma l'episodio che Sidonio Apollinare ${ }^{42}$ avrebbe celebrato poco dopo esaltando con eccesso retorico la vittoria riportata dall'imperatore Maioriano (457-461) nel 458 sulla banda di Mauri e Vandali che era sbarcata direttamente sulle coste della Campania: al di là del successo, il fatto dimostra che la provincia era fortemente esposta nonostante le difese di Napoli.

\footnotetext{
${ }_{29}$ SYMMACHI Relationes, 40, in O. SEEK (ed.), op. cit. (n. 6), pp. 279-317, a p. 311-312; L. CRIMACO, F. SOGLIANI, op. cit. (n. 26 ), pp. 199-202.

$3^{\circ}$ P. ARTHUR, op. cit (n. 25), p. 110.

${ }^{31}$ Ibidem, pp. 16-19, 139.

${ }^{32}$ SYMMACHI Epistulae, n. 46, op. cit. (n. 6), pp. 32-33.

${ }_{33}$ C. TH., XI 28, 2, op. cit. (n.27).

${ }^{34}$ G. GALASSO, Le città campane nell'alto medioevo, in Archivio Storico per le Province Napoletane, XXVIII, 1959, pp. 9-42; XXIX, 1960, pp. 9-53, quindi pubblicato in G. GALASSO, Mezzogiorno medievale e moderno, Torino, 1965, pp. 61-135.

35 J.M. MARTIN, Città e campagna: economia e società (secc. VII-XIII), in Storia del Mezzogiorno, III, Alto medioevo, Napoli, 1990, pp. 257-382, in part. p. 260 ove tende a differire il fenomeno perché non avrebbero avuto luogo fatti rilevanti prima della seconda metà del VI secolo.

${ }^{36}$ E. BOSCHI (ed.), Catalogo parametrico dei terremoti italiani, Bologna, 1999, p. 27, n. 14.

${ }^{37}$ I. CÀSSOLA, op. cit (n. 2), p. 144.

${ }^{38}$ C. TH., XI 28, 7, anno 413; XI 28, 12, anno 418, op. cit. (27) .

39 G. GALASSO, op. cit (n. 34), pp. 64-65.

${ }^{40} \mathrm{CIL}, \mathrm{X}, 1485$, op. cit. (n. 11).

${ }_{41}^{41}$ J. BELOCH, Campanien. Geschichte und Topographie des antiken Neapel und seiner Umgebung. Zweite vermehrte Ausgabe, Breslau, 189o, ed. italiana cit. di C. FERONE, G. PUGLIESE CARRATELLI Campania, Napoli, 1989, pp. 98-100.

${ }^{42}$ SIDONII APOLLINARIS Carmina, V, 385-440 (SIDONII APOLLINARIS Carmina tradotti da V. FAGGI, pref. di F. BANDINI, introd. e note di A.M. MESTURINI, Genova, 1981).
} 
9. Con la Sardegna e le province del Sannio e della Lucania, tenute ad una contribuzione più alta, la Campania (cui erano state sottratte Venafro e Isernia, assegnate fra 346 e 356 alla nuova provincia del Sannio ${ }^{43}$ ) doveva rifornire di suini e/o carne lavorata Roma, ove Valentiniano III aveva posto la propria sede; nel 452, poiché i Vandali dominavano il Tirreno e il trasporto dalla Sardegna era molto rischioso una novella di Valentiniano suddivise fra le province della terraferma l'onere gravante sull'isola ${ }^{44}$ che peraltro Geiserico avrebbe conquistato qualche anno dopo. Nella gravità della situazione generale che vede l'avvio di un processo di destrutturazione urbana solo Napoli (fig. 9) rappresenta un'eccezione: durante il V secolo alla città che probabilmente esportava i propri prodotti tessili ${ }^{45}$ continuarono ad affluire olio, vino e vasellame da mensa sia dall'Asia Minore, Siria, Cipro, Grecia che dall'Egitto e dal resto dell'Africa; a causa del continuo stato di guerra fra Roma e i Vandali nel corso del secolo finirono col prevalere le importazioni orientali su quelle africane ${ }^{46}$.

Se nei contesti di VII secolo sono ancora presenti anfore orientali e africane, dalla fine dell'VIII secolo-inizi IX è attestata una produzione locale, mentre dall'XI si registra la presenza di anfore 'a cannelures' importate dalla Sicilia ${ }^{47}$. Peraltro il declino della produzione ceramica tardoromana sembra indicare che il sistema delle nundinae, i mercati che in età antica si tenevano in giorni prestabiliti, collassò tra fine V-prima metà VI, soppiantato da fiere stagionali svolte soprattutto presso santuari e luoghi di culto ${ }^{48}$.

Per le sue attività economiche la città viene descritta da Cassiodoro come urbs ornata multitudine civium e sede di peregrina commercia ${ }^{49}$; effetti positivi avrebbe quindi prodotto la politica di rilancio delle città e della vita civile attuata all'inizio della dominazione ostrogota da Teoderico (fine V-inizi VI secolo): grazie ad essa l'aristocrazia latifondista riprese a risiedere nelle città, furono riaperte le scuole di grammatica e retorica e il livello culturale registrò un signi- ficativo innalzamento ${ }^{50}$. Ma dopo questo miglioramento di breve durata, l'eruzione del Vesuvio, detta di Pollena, datata tra il 472 e il $507-11^{51}$ e la peste iniziata nel 543 e rimasta endemica fino all'VIII secolo ${ }^{52}$ resero nuovamente critiche le condizioni generali: colpite dalle azioni belliche avviate nel 536 dai Bizantini per la riconquista della penisola, la Campania e la via Appia diventarono un campo di battaglia con conseguente abbandono delle campagne e aggravamento della situazione demografica ${ }^{53}$.

10. I centri urbani, di solito piccoli e di scarso rilievo, se si escludono Napoli, Capua e Benevento che costituivano le maglie dell'organizzazione amministrativa ed ecclesiastica, se riuscirono a resistere alla guerra goto-bizantina alla fine del VI non ressero ai fattori di recessione menzionati e all'occupazione del territorio conseguente alla conquista dei Longobardi ${ }^{54}$. In Campania furono abbandonate Minturnae, Suessula, Cuma, Sinuessa, Calatia, Forum Popilii (Carinola), Compulteria, Atella, Liternum, Abellinum, Aeclanum ${ }^{55}$.

Sebbene nel Mezzogiorno la presenza dei Longobardi, da qualcuno ritenuta incruenta ${ }^{56}$, sia stata inferiore e diversa da quella registrata nel Norditalia dalle numerose necropoli 'familiari' riferibili alle farae che attuarono la conquista perché la struttura dei gruppi e delle bande che agirono sotto Zottone e Arechi I è più simile a quella del comitatus germanico (gruppo militare 'specialistico'), risulta sostanzialmente valido per la regione il quadro delineato più in generale da Gregorio Magno ${ }^{57}$ circa il collasso della produzione agricola e della vita cittadina che ormai si raccoglie intorno alle chiese cattedrali e ai vescovi nelle sedi che non ne erano rimaste prive: pertanto anche in Campania l'età longobarda si connota come il momento finale della destrutturazione dell'organizzazione urbana avviata nella tarda età romana ${ }^{58}$, quando, nell'ambito del complessivo impoverimento e della generalizzata semplificazione degli impianti di uso collettivo e delle esigenze abitative, gli

\footnotetext{
43 D. VERA, op cit. (n.1).

${ }^{44}$ C. TH., Valent. Nov. 36 (C. TH., Valent. Nov. = VALEnTINIAN III, Novellae in TH. MOMMSEN, P. M. MEYER (ed.), Theodosiani libri XVI cum constitutionibus Sirmondianis et leges Novellae ad Theodosianum pertinentes, Berlino, Weidemann, 1905).

45 P. ARTHUR, op. cit (n. 25), p. 115.

${ }^{46}$ Ibidem, p. 141; riguardo alle importazioni orientali e africane in Italia cfr. P. DE VINGO Production and importation of Late Antique and Early Medieval pottery in Liguria, in J. DRAUSCHKE, R. PRIEN, A. REIS (eds.), Küche und Keller in Antike und Frühmittelalter: Tagungsbeiträge der Arbeitsgemeinschaft Spätantike und Frühmittelalter, 7. Produktion, Vorratshaltung und Konsum in Antike und Frühmittelalter; gemeinsame Tagung mit der Arbeitsgemeinschaft Römische Archäologie (Friedrichshafen, 30. Mai - 1. Juni 2012), Hamburg, 2014, pp. 257-304.

${ }^{47}$ P. ARTHUR, op. cit (n. 25), pp. 122-133.

${ }^{48}$ Ibidem, pp. 139-140.

${ }_{49}$ CASSIODORI Variae, VI, 23, 24 (CASSIODORI SENATORIS Variae, TH. MOMMSEN (ed.), in M.G.H., Auctores antiquissimi, XII, Bertolini, 1894); G. GALASSO, op. cit (n. 34), p. 65.

${ }^{50}$ B. LUISELLI, Storia culturale dei rapporti tra mondo romano e mondo germanico, Roma, 1992, p. 669.

${ }^{51}$ G. TOCCO SCIARELLI, L'età tardoantica nelle province di Salerno, Avellino e Benevento, in L'Italia meridionale in età tardoantica. Atti del XXXIV Convegno di studi sulla Magna Grecia. Taranto, 2-6 ottobre 1998, Napoli, 2000, pp. 243-266, a p. 244.

${ }^{52}$ J. N. BIRABEN, J. LE GOFF, La peste dans le haut Moyen Âge, in Les Annales. Économie, Sociéte, Civilisation, XXIV, 1969, pp. 1484-1510; N. CILENTO, Le origini della signoria capuana nella Longobardia minore (Istituto Storico Italiano per il Medio Evo, Studi storici, fasc. 69-70), Roma, 1966, p. 156.

53 V. VON FALKENHAUSEN, I Longobardi meridionali, in Storia d'Italia, III, Il Mezzogiorno dai Bizantini a Federico II, Torino 1983, pp. 249-364, in part. p. 12.

${ }^{54}$ L. DUCHESNE, Les évêchés d'Italie et l'invasion lombarde, in Mélanges d'archéologie et d'histoire, 22 (1903), pp. 83-116; J.M. MARTIN, op. cit (n. 35), pp. 265-267, 282-289; E. CUOZZO, Le diocesi di Aeclanum, Quintodecimo, Frigento, in Rassegna Storica Irpina, 7-10 (1993-94), pp. 15-35.

55 J.M. MARTIN, op. cit (n. 35), p. 266.

${ }^{56}$ B. FIGLIUOLO, Longobardi e Normanni, in G. PUGLIESE CARRATELLI (ed.), Storia e civiltà della Campania, II. Il Medioevo, pp. 37-86.

57 GREGORII I PAPAE Registrum Epistularum, P. EWALD, L. M. HARTMANN (eds), in M.G.H., Epistolae, I-II, Berlin, 1957; GREGORII MAGNI Dialogi, U. MORICCA (ed.) (Fonti per la Storia d'Italia dell'Istituto Storico Italiano per il Medioevo, 57), Roma, 1924.

${ }^{58}$ P. DELOGU, La fine del mondo antico e l'inizio del Medioevo: nuovi dati per un vecchio problema, in R. FRANCOVICH, G. NOYÉ (eds.), La storia dell'alto medioevo italiano (VI-X secolo) alla luce dell'archeologia. Convegno internazionale (Siena, 2-6 dicembre 1992), Firenze, 1994, pp. 7-29, a pp. 11-13.
} 


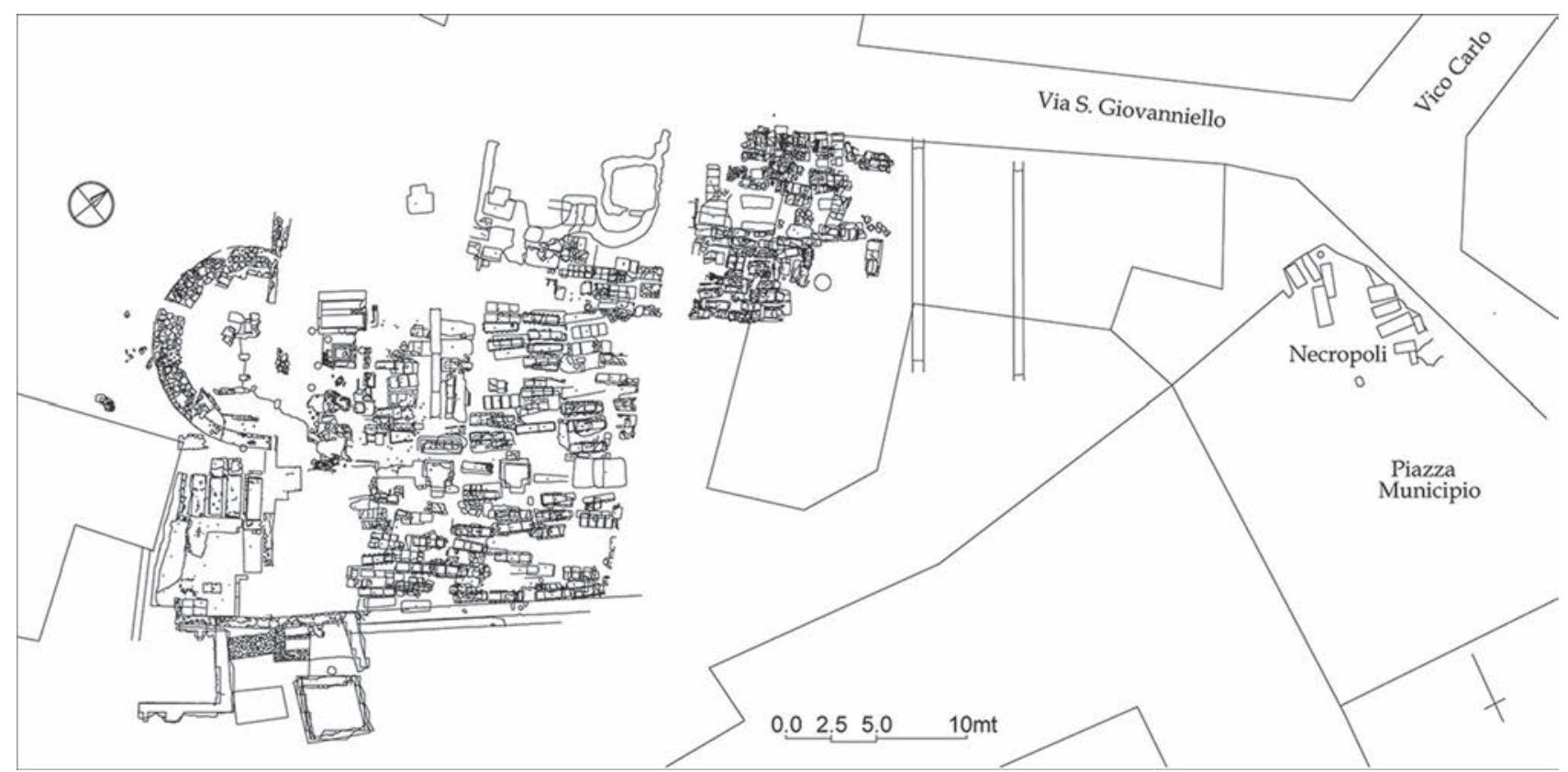

Fig. 8. Atripalda, Capo la Torre. Planimetria generale della basilica (elaborazione grafica New Archaeology, 2005).

edifici pubblici furono ridimensionati (o divennero cave di materiali da costruzione), gli spazi destinati all'uso sociale furono occupati da abitazioni private spesso debordanti sui tracciati stradali, la superficie abitata si ridusse vistosamente e luoghi di sepoltura vennero strutturati nelle città cui peraltro risultò possibile di continuare ad esistere proprio grazie alla trasformazione dello spazio urbano provocata anche dalla diffusione del Cristianesimo e dalla conseguente organizzazione della comunità ecclesiastica che portò, come nel caso di Abellinum, sede di diocesi dalla fine del V secolo, alla formazione di un nucleo paleocristiano extra moenia (una basilica dei primi decenni del IV) che peraltro, tra la fine del V e gli inizi del VI fu abbandonato, forse a causa di quegli stessi eventi che stavano provocando la decadenza dell'insediamento romano sulla collina della Civita ${ }^{59}$. Le sacre spoglie dei martiri di Abellinum vennero quindi venerate fin dall'altomedioevo nello Specus Martyrum, un ipogeo situato nella cripta della collegiata di Sant'Ippolisto, intorno al quale si sarebbe sviluppato l'attuale abitato di Atripalda ${ }^{60}$. Nei pressi dello Specus fu edificata una basilica cristiana (fig. 8) divisa in tre navate con orientamento nord ovest-sud est e con l'abside ad ovest; presentava dimensioni notevoli: la larghezza complessiva è di $23 \mathrm{~m}$, la lunghezza indagata di 33; la navata centrale è larga $13 \mathrm{~m}$, mentre le laterali 5 . I pilastri, conservati in altezza per circa $\mathrm{m} 1,50$, sono realizzati in opus testaceum con fondazione costituita da materiali di spoglio; distano tra loro m 3,50 ed erano probabilmente raccordati da archi a tutto sesto. Le murature perimetrali dell'edificio sono realizzate in opus vittatum. Nella navata centrale è stato rinvenuto il basamento, costituito da blocchi calcarei di spoglio, che separava l'area destinata ai fedeli dal presbiterio; all'interno di quest'ultimo è stata trovata una struttura rettangolare, rivestita di marmo, probabilmente destinata ad accogliere delle reliquie. Lo spazio delle navate fu occupato interamente da sepolture. Durante le varie campagne di scavo realizzate nell'area sono state rinvenute oltre 500 tombe databili tra la fine del III ed il VI secolo e 116 iscrizioni attribuite, per la presenza della data consolare, al periodo tra il 453 ed il 558. A queste ne vanno aggiunte 15 rinvenute nel corso del XIX secolo e i due epitaffi custoditi nello specus martyrum. Le iscrizioni contribuiscono significativamente alla conoscenza della società dell'epoca la cui élite era costituita principalmente da personaggi di spicco del clero cittadino ${ }^{61}$.

11. Il processo di destrutturazione urbana che non riesce a controbilanciare alcuni indubbi aspetti di continuità insediativa e di persistenza edilizia (come le mura o il reticolo urbano di età classica) e che si concretizza nella creazione di spazi verdi destinati a orti e pascoli e di depositi la cui consistenza è frutto del collasso del sistema fognario e del diffuso accumulo di rifiuti (anche a forte componente organica), è stato registrato dalle indagini archeologiche condotte a Napoli (fig. 9) che hanno evidenziato trasfor-

59 M. ROTILI, Hirpinia christiana tardoantica e altomedievale: recenti contributi della ricerca archeologica, in A.V. NAZZARO (ed.), Giuliano d'Eclano e l'Hirpinia christiana. Atti del Convegno, 4-6 giugno 2003, Napoli, 2004, pp. 265-285. Risale a questa fase di decadenza la trasformazione di molti edifici, documentata da rinvenimenti archeologici. Esemplificativi al riguardo sono i rifacimenti operati nel settore meridionale, tra atrio evestibolo, di una domus di tipo pompeiano (appartenuta probabilmente a Marcus Vipsanius Primigenius, liberto di Vipsanio Agrippa, genero di Augusto), le trasformazioni di un imponente edificio terrazzato presumibilmente a carattere pubblico e infine la presenza di una serie di sepolture lungo il cardo che delimita la suddetta domus sul lato orientale. Alla destrutturazione urbana corrispose un implementarsi della vita e delle attività dei distretti rurali, confermato da una serie di attestazioni; M. FARIELLO SARNO, C. LAMBERT, Il territorio di Abellinum in età tardo antica e altomedievale: dati archeologici e documenti epigrafici, in C. EBANISTA, M. ROTILI (eds.), La Campania fra tarda antichità e alto medioevo. Ricerche di archeologia del territorio. Atti della Giornata di studio, Cimitile, 10 giugno 2008, Cimitile, 2009, pp. 49-73.

${ }^{60}$ M. FARIELLO SARNO, Abellinum paleocristiana, in G. COLUCCI PESCATORI, E. CUOZZO, F. BARRA (eds.), Storia illustrata di Avellino e dell'Irpinia, I. L'Irpinia antica, Pratola Serra 1996, pp. 161-176; EAD, Il complesso paleocristiano di S. Ippolisto-Capo La Torre. Nuove scoperte e prospettive di ricerca, in Rassegna Storica Irpina, 3-4 (1991), pp. 11-34.

${ }^{61}$ G. COLUCCI PESCATORI, V. DI GIOVANNI, Atripalda. La ricerca archeologica: Loc. Capo La Torre. La basilica paleocristiana, in Notiziario SBA Salerno, Avellino, Benevento, 1, 2005, pp. 21-22. 


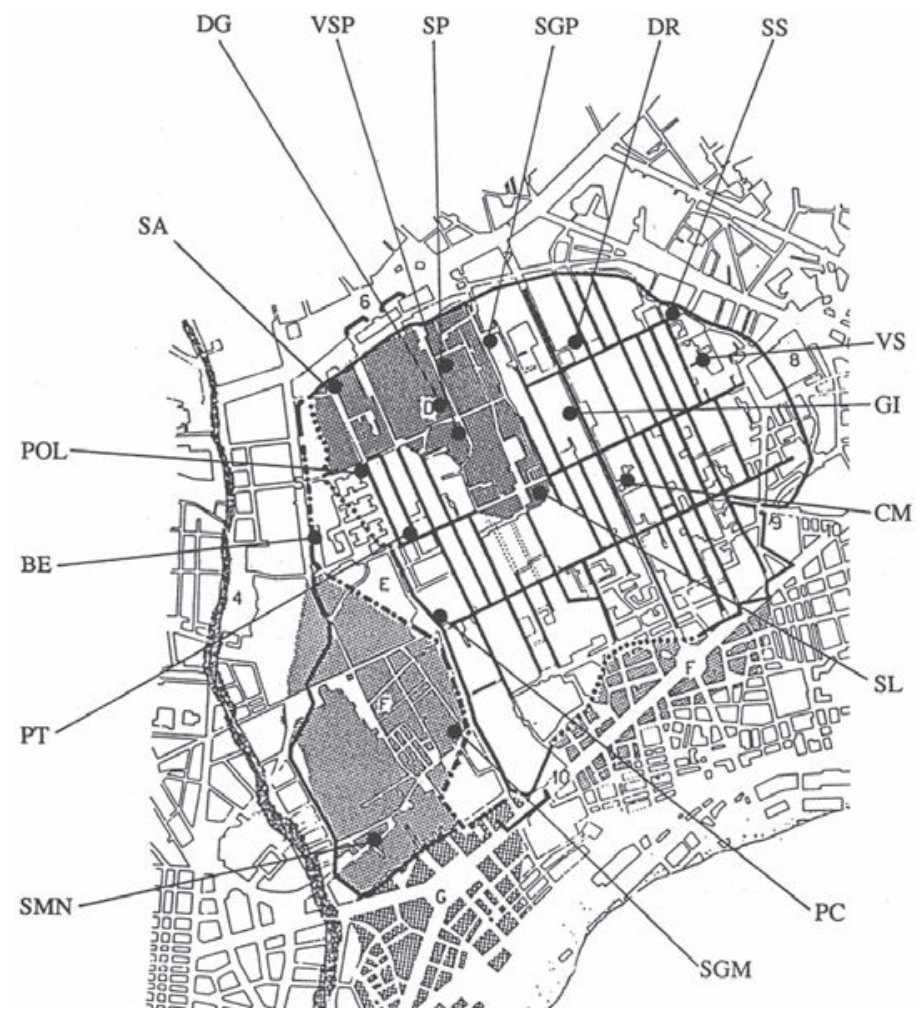

Fig. 9. Napoli. Scavi di archeologia tardoantica e altomedievale: SS, Via Santa Sofia (1983); VS/VSg, Vico della Serpe (1985)/Vico della Serpe (giardino) - Santa Maria d'Agnone (1986-88); CM, Via Carminiello ai Mannesi (1983-84); GI, Girolomini (1984); GIc, Girolomini - chiostro (1984); SGP, San Giovanni in Porta (1986); SP, Santa Patrizia (1983-86); VSP, Vico San Paolo, 42 (1984-86); PT, Pietrasanta (Santa Maria Maggiore, 198485); SMN, Santa Maria la Nova (1983); BE, Piazza Bellini (1984); SMA, Santa Maria Antesaecula (1983); PC, Palazzo Corigliano (1982-84); SA, Sant'Aniello a Caponapoli (1982-83); CSA, Chiesa di Sant'Aniello (1979); POL, Policlinico (1983); DG, ex De Giaxa property, Via L. Armanni (1985), DR, Donnaregina (1988); SGM, San Giovanni Maggiore (1987); SC, San Costanzo, Capri (1990); VB, Via Botteghelle, Ponticelli (1986); PBL, Via Bartolo Longo, Ponticelli (1986); SL, San Lorenzo Maggiore.

mazioni analoghe a quelle documentate a Roma, Brescia, Verona, Luni ${ }^{62}$, in particolare va segnalata la trasformazione in discarica, in età ostrogota, di un grande edificio abbandonato in epoca tardoromana, mentre alla formazione di vaste aree coltivate fanno riferimento i depositi di dark earths individuati in varie stratigrafie ${ }^{63}$ : le analisi paleobotaniche sulle terre nere di vico della Serpe e via S. Paolo hanno permesso di identificare semi di uva, susine, noci e nocciole, mentre a S. Patrizia la flottazione degli strati di VIII-IX secolo ha restituito fra l'altro avanzi di cavolo e spinaci ${ }^{64}$. Le verdure, con ogni probabilità, erano coltivate negli orti urbani o in quelli prossimi alle mura, l'uva nei vigneti vicini alla città. Semi di lino sono stati trovati in contesti di VIII-IX secolo, prima che la documentazione attesti l'importanza della relativa produzione napoletana. Sul consumo di carne, le indagini archeologiche condotte in diversi punti (S. Patrizia,
Girolamini, via S. Paolo, Carminiello ai Mannesi) indicano che fino al V secolo l'animale più macellato fu il maiale, successivamente soppiantato da ovini e caprini; solo dalla fine dell'VIII si ritornò alla situazione attestata nella tarda antichità ${ }^{65}$. Questi dati possono essere interpretati come un segnale del crescente impoverimento e della ruralizzazione dell'abitato urbano, a dispetto della presenza di scriptoria monastici specializzati nella produzione libraria, di cantieri navali e di laboratori artigianali cui possono essere attribuiti i rari manufatti metallici e in vetro trovati negli scavi. La scarsa frequenza di ceramica bizantina sembrerebbe testimoniare gli sporadici contatti con Bisanzio sia prima che dopo la conquista normanna. Al contrario la produzione monetaria risulta strettamente correlata all'autorità imperiale e modellata sulle emissioni bizantine anche dopo che il controllo della zecca napoletana fu assunto direttamente dal duca Stefano II, alla metà dell'VIII secolo; peraltro già all'epoca del duca Basilio, forse su autorizzazione del basileus Costante II nel corso della sua visita alla città nel 663, era stata impiantata una zecca permanente la cui produzione è nota con certezza fino al IX secolo ${ }^{66}$.

12. Le mura ripristinate da Valentiniano III furono restaurate dopo l'espugnazione da Belisario: 7 mirificas turres ottagonali ed esagonali vennero allora edificate ai principali angoli della cinta. Le difese, parzialmente distrutte da Totila, furono quindi rinnovate da Narsete ${ }^{67}$ che fece ampliare la cinta ad ovest e a sud includendo nuove zone come la regio Albiensis. In quest'epoca alla basilica di S. Restituta, ritenuta quasi concordemente di fondazione costantiniana, nell'insula episcopalis in cui è presente anche il battistero di S. Giovanni in Fonte, si aggiunse la basilica fatta erigere dal vescovo Stefano agli inizi del VI secolo e che dal suo fondatore prese il nome di 'Stefania': com'è noto essa fu demolita tra la fine del Duecento e gli inizi del secolo successivo in rapporto alla costruzione del duomo angioino. Le chiese paleocristiane di Napoli meritano studi più approfonditi e nuove indagini archeologiche che possano meglio evidenziare i legami con la successiva architettura religiosa di età ducale solo in minima parte influenzata dall'ambiente bizantino. Scarsamente noti dal punto di vista archeologico risultano invece i monasteri greci e latini attestati dalle fonti ad eccezione di S. Patrizia (già dedicato ai Ss. Nicandro e Marciano), ove gli scavi condotti tra il 1983 e il 1986 hanno portato in vista i resti di un probabile refettorio del VI e significative testimonianze di cultura materiale ${ }^{68}$.

I dati archeologici su commerci e scambi evidenziano che Napoli, città di consumatori in età romana, divenne nell'alto medioevo una città-stato caratterizzata da continuità insediativa, con una produzione di mercato e con funzioni di emporio internazionale in grado di rifornire anche l'entroterra longobardo. Se nei secoli VI-VII si registrano lo spopolamento e la crescente ruralizzazione dell'habitat urbano,

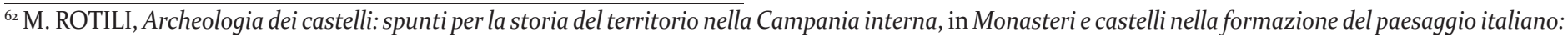
la viabilità. Seminario di studi, Benevento 20 novembre 1998, in Archivio Storico del Sannio, n. s., V, 2000/2, pp. 7-40, in part. pp. 9-10.

${ }_{63}^{6}$ P. ARTHUR, Lo scavo, in P. ARTHUR (ed.), Il complesso archeologico di Carminiello ai Mannesi, Napoli (scavi 1983-1984), Galatina, 1994, pp. 51-70, in part. pp. 58, 68; ID., op. cit. (n. 25), pp. 52-55.

${ }^{64}$ Ibidem, p. 113.

${ }^{65}$ Ibidem, pp. 115-117.

${ }^{66} \mathrm{Ibidem}, \mathrm{pp} .134-136$.

${ }^{67}$ G. GALASSO, op. cit (n. 34), p. 73.

${ }^{68}$ P. ARTHUR, op. cit (n. 25), p. 155.
} 


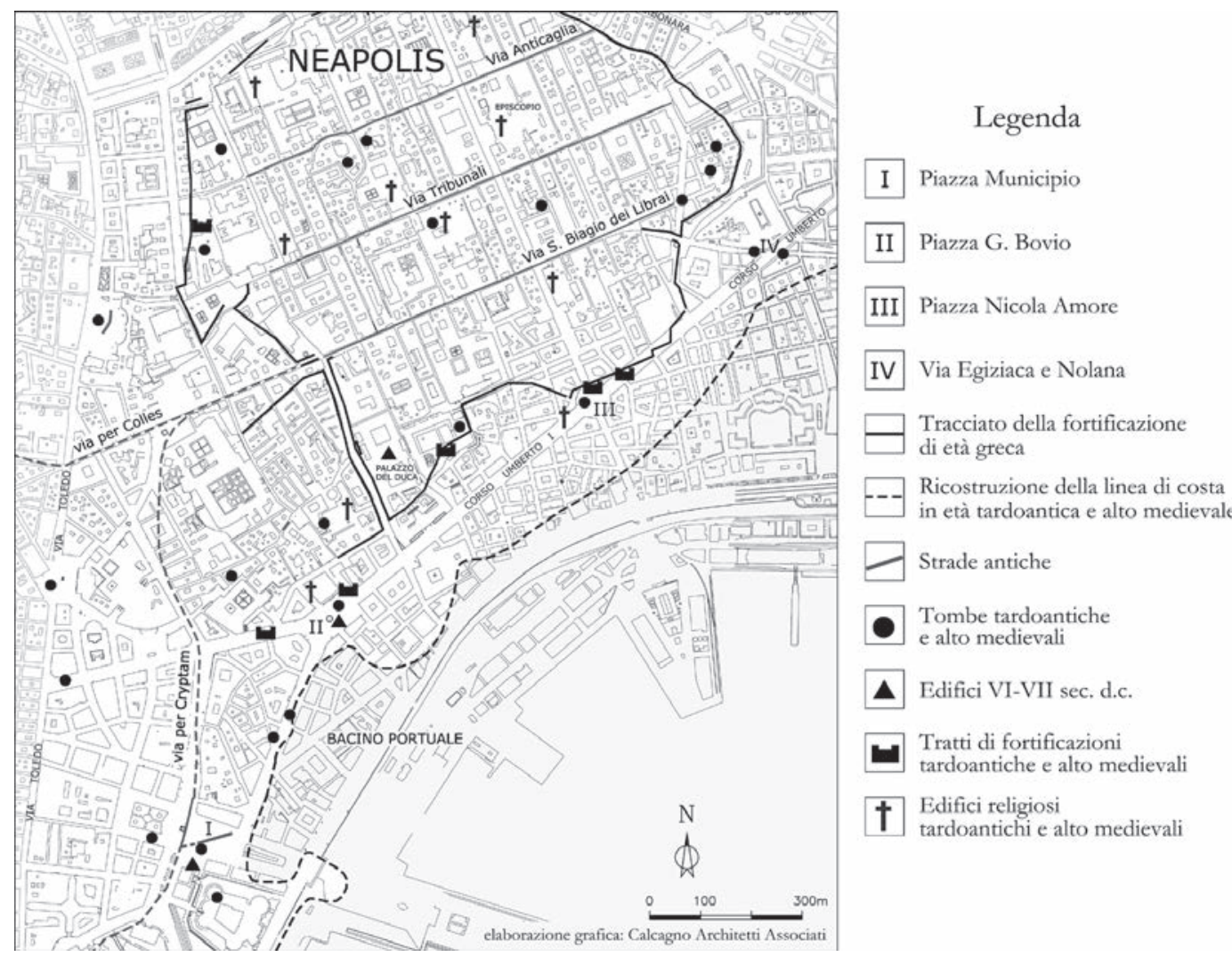

Fig. 10. Il paesaggio costiero di Neapolis in età tardoantica e altomedievale, planimetria con i principali monumenti e la ricostruzione della linea di costa e dell'insenatura portuale.

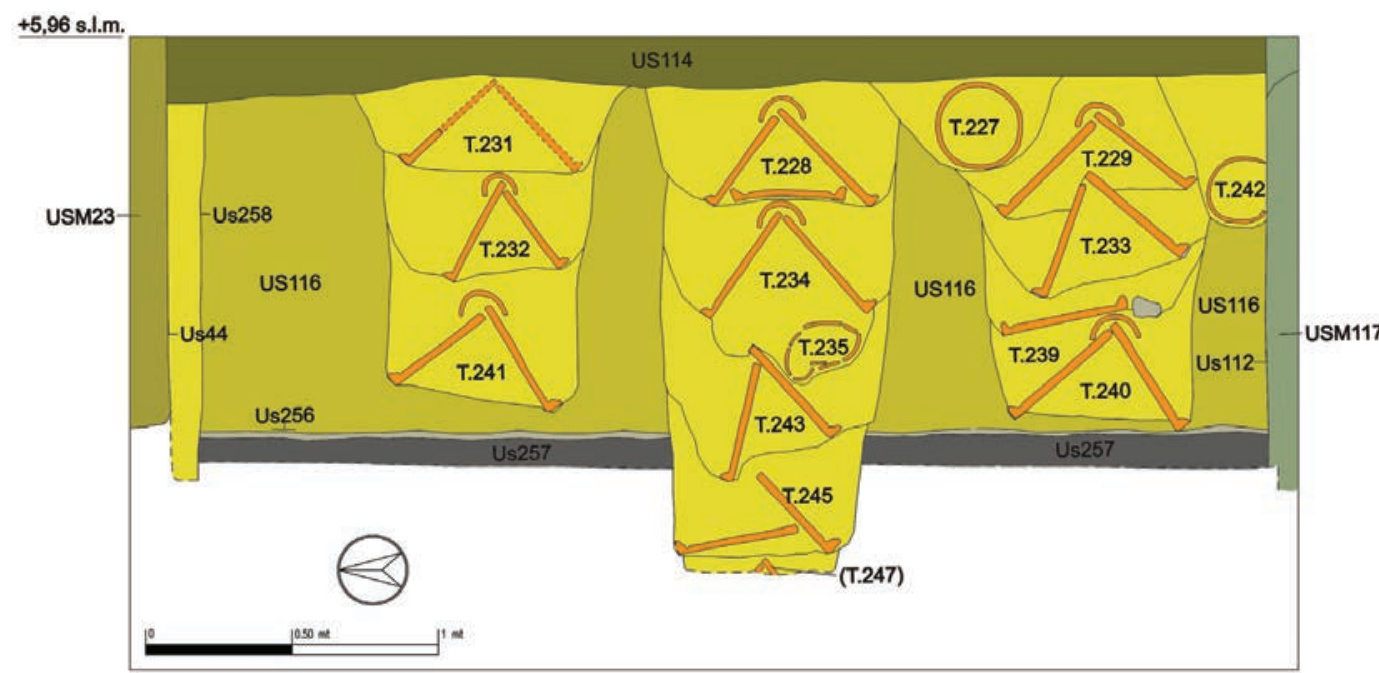

Fig. 11. Corso Umberto angolo Via Nolana, tombe a cappuccina sovrapposte della seconda metà del VII secolo. contrastarne il successo nel IX secolo a beneficio di Salerno, centro di scarsa rilevanza sulla Capua-Rhegium fino alla rifondazione di Arechi II intorno al $774^{70}$; e nel 1039 si registra un'altra azione salernitana contro la città che tuttavia mantenne la sua sostanziale indipendenza fino ai Normanni.

In anni recenti nel capoluogo campano significative scoperte sono state permesse dagli scavi archeologici preventivi (fig. 10) condotti in rapporto alla realizzazione delle stazioni della linea 1 della metropolitana ("Municipio" in piazza Municipio, "Toledo" in via Diaz, "Università" in piazza Bovio, "Duomo" in piazza Nicola Amore) e della linea 6 ("Arco Mirelli", "S. Pasquale", "Chiaia" in piazza S. Maria degli Angeli, "Municipio"). L'intervento ha consentito di esplorare l'antico paesaggio del litorale, finora scarsamente conosciuto per la profondità dei resti archeologici e la presenza in superficie dell'acqua di falda. In particolar modo sono state documentate le trasformazioni della città in età tardoantica e altomedievale, quando Napoli passò sotto il dominio bizantino. Fra VI e VII fu ricostruita la cinta muraria, come dimostrano ri risultati ottenuti nei siti di piazza Nicola Amore e piazza Giovanni Bovio: nella prima è emersa una poderosa cortina muraria che riveste quella di età greca, nella seconda una torre che riutilizza decorazioni architettoniche in marmo di un arco onorario degli inizi del dalla fine dell'VIII, conquistata l'autonomia da Bisanzio, la città viene gradualmente riurbanizzata con il conseguente trasferimento di molte attività rurali di nuovo all'esterno delle mura e con un impiego del territorio che permise di produrre il surplus destinato all'esportazione il che contribuì alla ripresa del commercio. Nell'alto medioevo la proiezione marinaresca e mediterranea viene peraltro gradualmente sostituita dall'iniziativa mercantesca di Amalfi che si afferma come esportatrice di prodotti agricoli, tessuti di lino, materiale per attrezzature navali, legname, schiavi verso i paesi mussulmani e le aree bizantine grazie all'investimento di capitali accumulati nella pur circoscritta attività agricola dei suoi abitanti ${ }^{69}$. I Longobardi di Benevento tentarono di
III secolo d.C. Agli inizi del V il progressivo insabbiamento dell'insenatura portuale determinò l'avanzamento della linea di costa, con una nuova dislocazione del porto probabilmente ad est, verso piazza Bovio. Dalla metà del VI secolo gli spazi ormai sottratti al mare vennero occupati da officine artigianali per vetro e metallo, da nuclei di sepolture e da edifici legati alle attività portuali. Nell'VIII e nel IX tutta la fascia costiera fu oggetto di un fenomeno di abbandono e solo in età bassomedievale si affermerà una nuova vitalità urbana.

13. La distribuzione diffusa dei nuclei sepolcrali risalenti all'epoca tardoantica e altomedievale a Napoli costituisce un segno caratterizzante delle nuove modalità insediative.

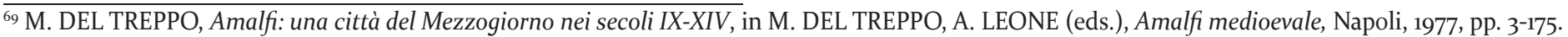

$7^{70}$ P. DELOGU, Mito di una città meridionale, Napoli, 1977. 


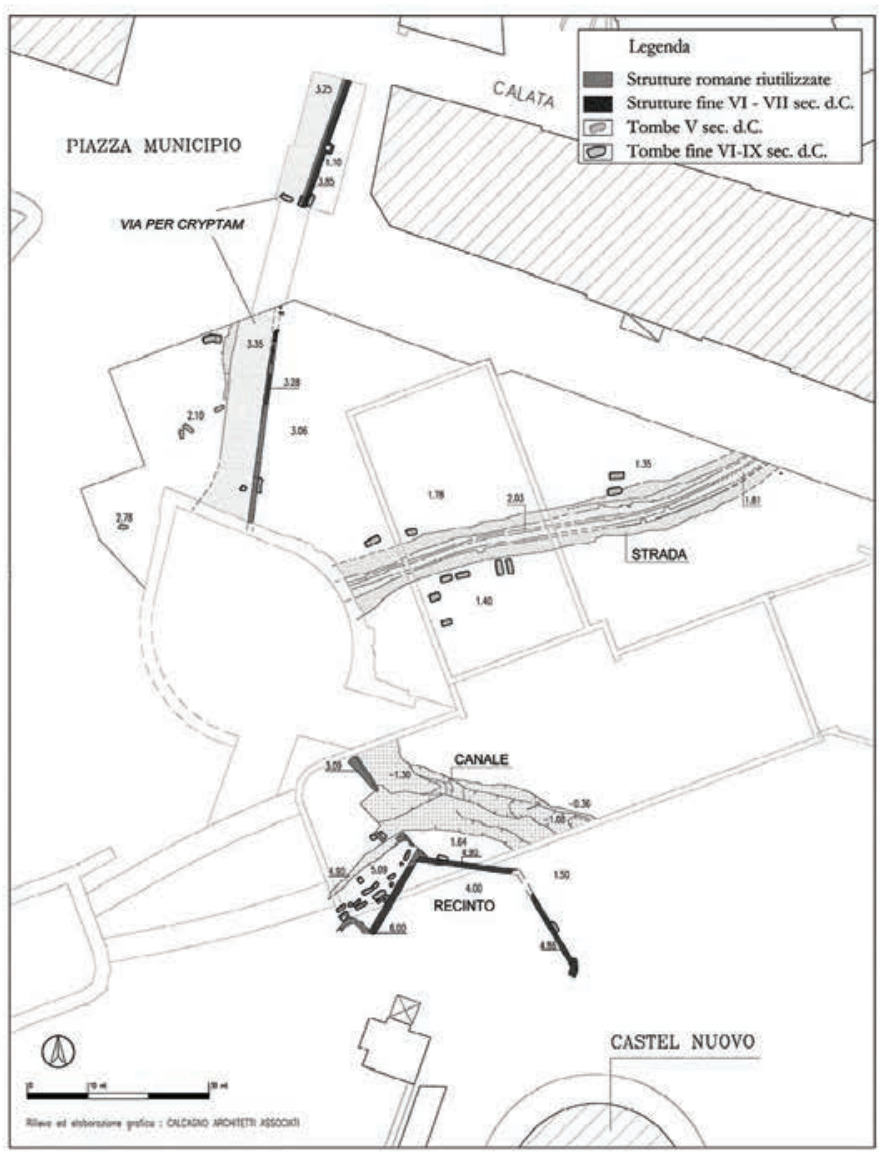

a

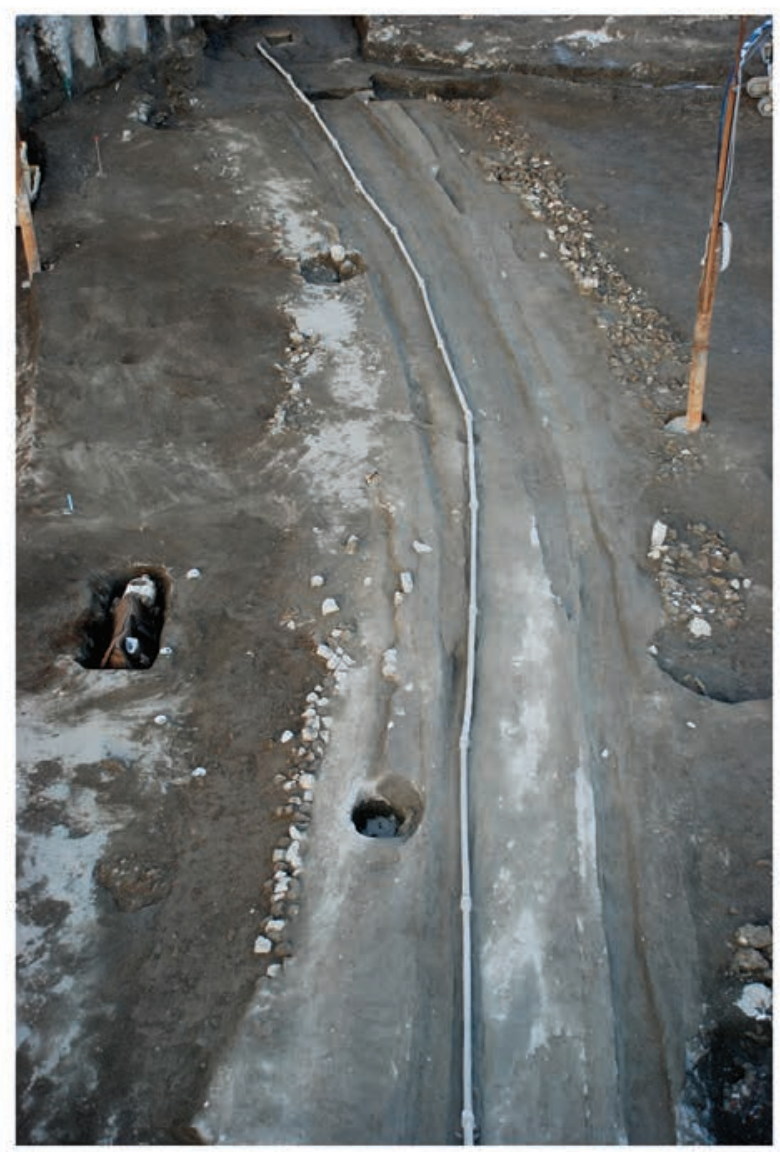

$\mathrm{b}$

Fig. 12. a - Piazza Municipio, planimetria con i rinvenimenti di età tardoantica e altomedievale; $b$ - Piazza Municipio, foto obliqua dei rinvenimenti di età tardoantica e altomedievale.

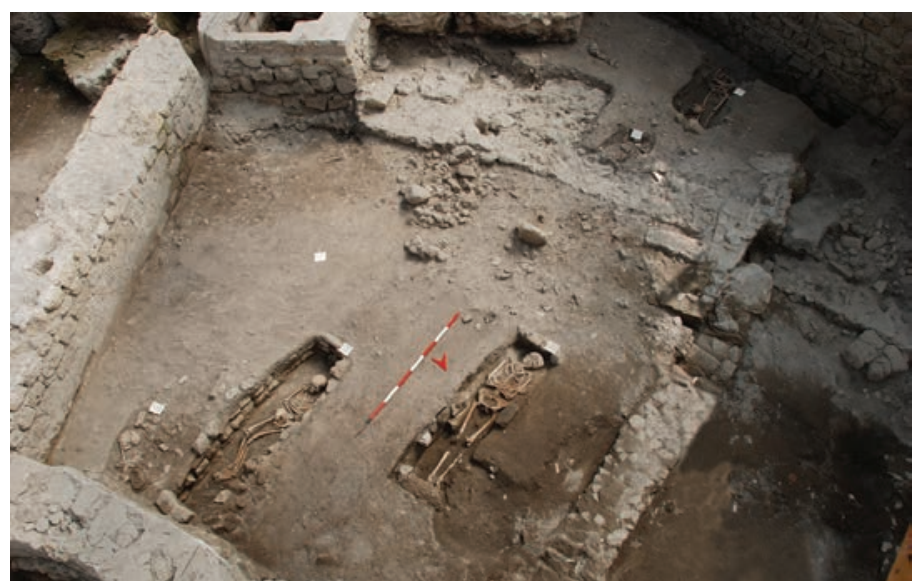

Fig. 13. Piazza Municipio, veduta delle sepolture poste ad ovest del recinto, tagliate in parte dalle fondazioni basso medievali.

Rinvenimenti tombali testimoniano l'esistenza di una consistente necropoli di carattere unitario, estesa da via Egiziaca sino a via Nolana (fig. 11), in un'area posta nei pressi di una strada che usciva dalla porta furcillensis. Non è stata ancora eseguita un'analisi sistematica dell'organizzazione interna del sepolcreto ma sembra ipotizzabile che le tombe più antiche e rade fossero collocate in via Egiziaca, quelle fitte e più tarde in via Nolana. Una necropoli occupava l'area del complesso del santuario dei Giochi Isolimpici Napoletani (Piazza Nicola Amore) di cui è stato individuato un tempio risalente al primo quarto del I secolo d.C., il Caesareum ${ }^{71}$. L'edificio sacro fu ricostruito alla metà del II secolo d.C. e grazie a vari rifacimenti durò sino almeno al IV inoltrato. Nel V secolo il complesso fu progressivamente abbandonato, anche a causa dell'impaludamento, fino a quando fu definitivamente distrutto alla metà del VI. Poco dopo, a nord del tempio, venne edificata una poderosa cortina difensiva che foderava le strutture della fortificazione di età greca ${ }^{72}$. La zona extramuranea, dalla fine del VI fino alla metà del IX secolo, fu adibita ad area sepolcrale come testimoniato dalle 33 tombe rinvenute. Il recente scavo di Piazza Bovio (figg. 12-13) ha documentato la presenza di strutture connesse alla produzione del vetro e del metallo databili alla metà del VI secolo; dalla fine dello stesso, sino agli inizi del VII l'insediamento artigianale fu dotato di un piccolo sepolcreto

\footnotetext{
${ }_{71}$ Per la descrizione del tempio e delle fasi costruttive cfr. I. BRAGANTINI et alii, Lo scavo di piazza Nicola Amore: le fasi edilizie e decorative del complesso monumentale, in I. BRAGANTINI (ed.) 2010, Actes du Xe Colloque international de l'Association Internazionale pour la Peinture Murale antique (Napoli 17-21 settembre 2007), Napoli, 2010 pp. 607-622; D. GIAMPAOLA, V. CARSANA, Sepolture di età tardoantica e altomedievale della fascia costiera di Neapolis: un aggiornamento, in C. EBANISTA, M. ROTILI (eds.), Territorio, insediamenti e necropoli fra tarda antichità e alto medioevo. Atti dei Convegni internazionale Cimitile-Santa Maria Capua Vetere, 2013-2014, Napoli, 2016, pp. 286-308, in part. p. 290.

${ }^{72}$ Sulla fortificazione e l'area sepolcrale di epoca tardo antica e altomedievale a piazza Amore cfr. D. GIAMPAOLA, Dagli studi di Bartolommeo Capasso agli scavi della Metropolitana: ricerche sulle mura di Napoli e sull'evoluzione del paesaggio costiero, in Napoli Nobilissima, V, I-II, pp. 35-56; D. GIAMPAOLA et alii, Napoli: trasformazioni edilizie e funzionali della fascia costiera, in G. VITOLO (ed.), Le città campane tra tarda antichità e alto medioevo, Napoli, 2005, pp. 219-247; D. GIAMPAOLA, V. CARSANA, op. cit. (n. 71), p. 290.
} 
(20 tombe) ${ }^{73}$. Nel corso della prima metà del VII, dopo la defunzionalizzazione dell'area e la cessazione del suo uso funerario, fu costruito un complesso edilizio di circa 700 $\mathrm{m}^{2}$, con magazzini per lo stoccaggio di merci ${ }^{74}$. Esso era probabilmente in prossimità del nuovo porto ed era immediatamente esterno alla fortificazione rinvenuta lungo il lato settentrionale della piazza, davanti all'edificio della Borsa. Il perimetro difensivo era costituito da una cortina, databile fra V e VI secolo, alla quale alla metà del VII fu addossata una torre, a guardia di una postierla attraverso la quale entrava in città un asse stradale ${ }^{75}$; i magazzini furono abbandonati e successivamente distrutti nel IX secolo.

Nei pressi di Piazza Municipio è stata individuata l'antica insenatura portuale di età augustea con una banchina in opera cementizia. È stato rinvenuto anche un edificio termale, risalente alla stessa epoca, sul cui margine orientale si sviluppava un ampio asse viario con orientamento nord-sud che collegava Neapolis al suo porto, probabilmente un tratto della via per cryptam che poi proseguiva verso Puteoli e i Campi Flegrei. In età tardoantica l'edificio fu in gran parte riutilizzato come insieme di magazzini per il deposito di derrate e altri materiali.

Lungo la via per cryptam e gli assi stradali di collegamento tra la stessa strada e il porto, dal V secolo al VII furono sistemate numerose sepolture. Un ulteriore nucleo cimiteriale di età altomedievale è venuto in luce nella zona di scavo a nord dell'attuale fossato di Castel Nuovo: le tombe erano state realizzate sugli strati di macerie dell'edificio termale di età medio imperiale.

Dall'esame dei nuclei sepolcrali si individuano sostanzialmente tre momenti cronologici diversi. Le tombe più antiche, della metà-fine del V secolo, attestate in via Egiziaca e in piazza Municipio (figg. 11-12), sono sporadiche ed esigue numericamente; sembrano rispondere ad una situazione di emergenza, che non è inverosimile associare alle vicende militari determinate dalle scorrerie barbariche che coinvolgono la città.

Più consistenti e articolati appaiono i nuclei sepolcrali dalla fine del VI a tutto il VII secolo. Questo periodo coincide con il momento del riaffermarsi e del consolidarsi del dominio bizantino dopo la fine della guerra greco-gotica: le evidenze archeologiche indicano le trasformazioni della struttura urbana, caratterizzata da tempo dal declino e ulteriormente provata dai drammatici eventi bellici. Un forte elemento da sottolineare è il valore, nel periodo considerato, della viabilità come luogo di attrazione dei sepolcreti. Nell'VIII e soprattutto nel IX secolo diminuiscono i nuclei funerari, anche in rapporto al fenomeno della loro concentrazione nei complessi ecclesiastici e nelle aree ad essi circostanti $\mathrm{i}^{7}$.

14. Anche a Salerno sono attestati nuclei funerari urbani risalenti alla fase tardoantica- altomedievale. Le terme del I o II secolo d.C., dopo un periodo di abbandono in cui vennero invase da uno strato alluvionale, furono riutilizzate

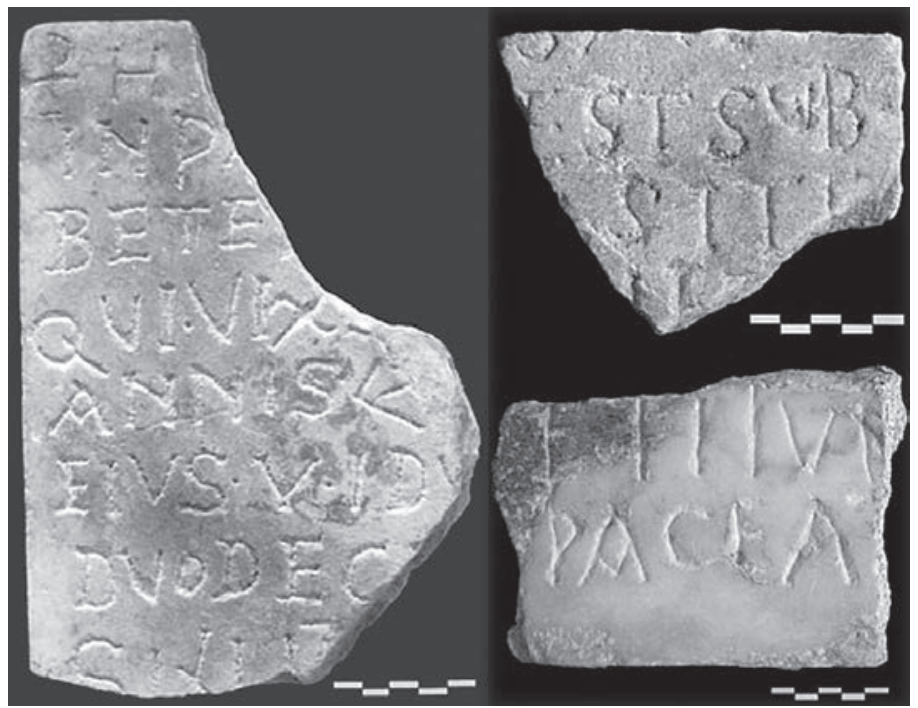

Fig. 14. Iscrizioni funerarie, scavo in via Vicinanza, Salerno.

verso la fine del $\mathrm{V}$ come luogo di sepoltura, conservando tale funzione fino al VII, quando vennero probabilmente abbandonate ${ }^{77}$.

Un'altra area sepolcrale è stata rinvenuta in recenti indagini archeologiche condotte durante i lavori di ripavimentazione e rifacimento della rete fognaria del corso Vittorio Emanuele. La necropoli era costituita da tre nuclei di sepolture in parte obliterate dalle fondazioni e sottoservizi di edifici moderni. Databile a partire dal II secolo a. C. al V-VI d. C., si era sviluppata nel tempo in maniera non estensiva, ma attraverso sovrapposizioni di depositi lungo la linea del litorale che ora corrisponde al corso principale della città.

La parte di necropoli messa in luce durante gli scavi era sigillata da uno strato di notevole spessore, costituito da terra e abbondante materiale archeologico decontestualizzato, riferibile all'alluvione che interessò Salerno tra la fine del IV secolo d. C. e l'inizio del V. Le sepolture sono state trovate alla quota di 2-3 $\mathrm{m}$ al di sotto dell'attuale piano di calpestio ed erano legate a poderose strutture murarie già in posto, con orientamento nord-ovest/sud-est. Rivestite da uno strato di intonaco, tali strutture erano state costruite con ciottoli, tufo e un legante molto compatto su un terreno sabbioso formatosi in seguito ad una mareggiata. Esse delimitavano l'area sepolcrale nella quale le tombe più antiche (sulle quali ne sarebbero state deposte altre) erano state sono realizzate nel terreno sabbioso e in appoggio alle strutture stesse. Il rinvenimento di tre iscrizioni funerarie frammentarie in lingua latina, databili in base ai caratteri paleografici e alla tecnica di incisione al VI secolo, documenta che la necropoli fu attiva anche dopo l'alluvione di fine IV - inizi $\mathrm{V}^{7}$. Le tre iscrizioni (fig. 14) risultano frutto di una pratica artigianale esercitata da personale ormai disabituato alla grande produzione e con scarsa padronanza della tecnica epigrafica ${ }^{79}$. Dall'esame dei testi si può comprendere che la committenza di tali prodotti era costituita da individui dalle ridotte possibilità economiche, però consapevoli del

\footnotetext{
${ }_{73}$ S. FEBBRARO, Il quartiere artigianale e la necropoli, in Napoli. La città e il mare, Napoli, 2010, pp. 57-61; GIAMPAOLA, V. CARSANA, op. cit. (n. 71), p. 291. ${ }^{74}$ B. RONCELLA, I magazzini, in Napoli la città e il mare, Napoli, 2010, pp. 62-68; D. GIAMPAOLA, V. CARSANA, op. cit. (n. 71), p. 291.

${ }^{75}$ M. GENTILE, La fortificazione bizantina, in Napoli. La città e il mare, Napoli, 2010, pp. 51-56; D. GIAMPAOLA, V. CARSANA, op. cit. (n. 71), p. 291.

${ }^{76}$ Ibidem, pp. 299-302.

77 P. DELOGU, Longobardi e Romani: altre congetture, in S. GASPARRI, P. CAMMAROSANO (eds.), Langobardia, Udine, 1990, pp. 111-167, a p. 148.

${ }^{78}$ R. ALTOBELLO, Salerno. Lo scavo di alcune sepolture in via Vicinanza, in Salternum, XIV, nn. 24-25, Salerno, 2010, pp. 119-124.
} 


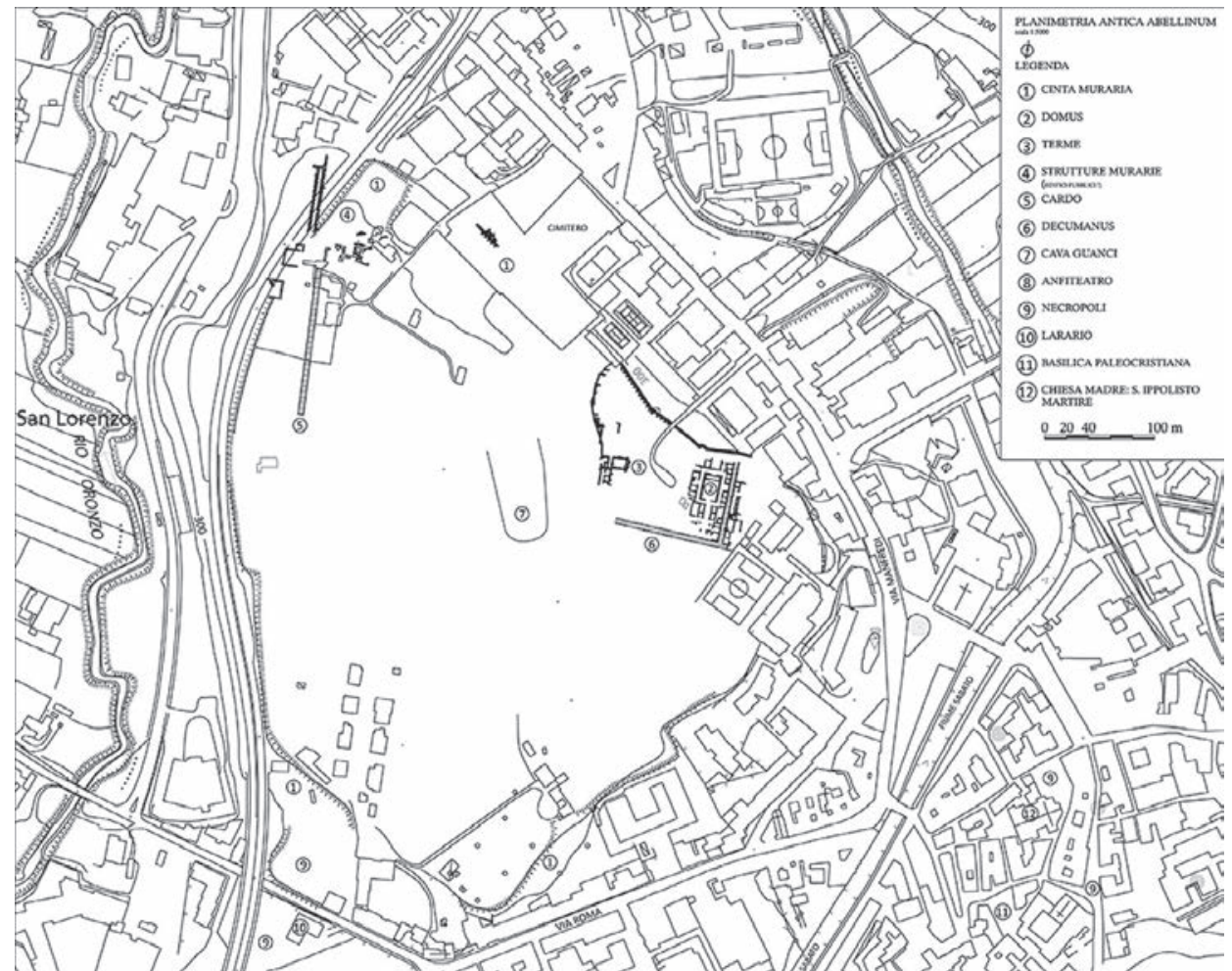

Fig. 15. Pianta schematica dell'antica Abellinum (Elaborazione grafica dell'arch. M.M. Colucci).

1. Cinta muraria. 2. Domus. 3. Terme. 4. Strutture murarie (edifici pubblici?). 5. Cardo. 6. Decumanus.

7. Cava Guanci. 8. Anfiteatro. 9. Necropoli. 10. "Larario». 11. Basilica paleocristiana. 12. Chiesa Madre di S. Ippolisto martire.

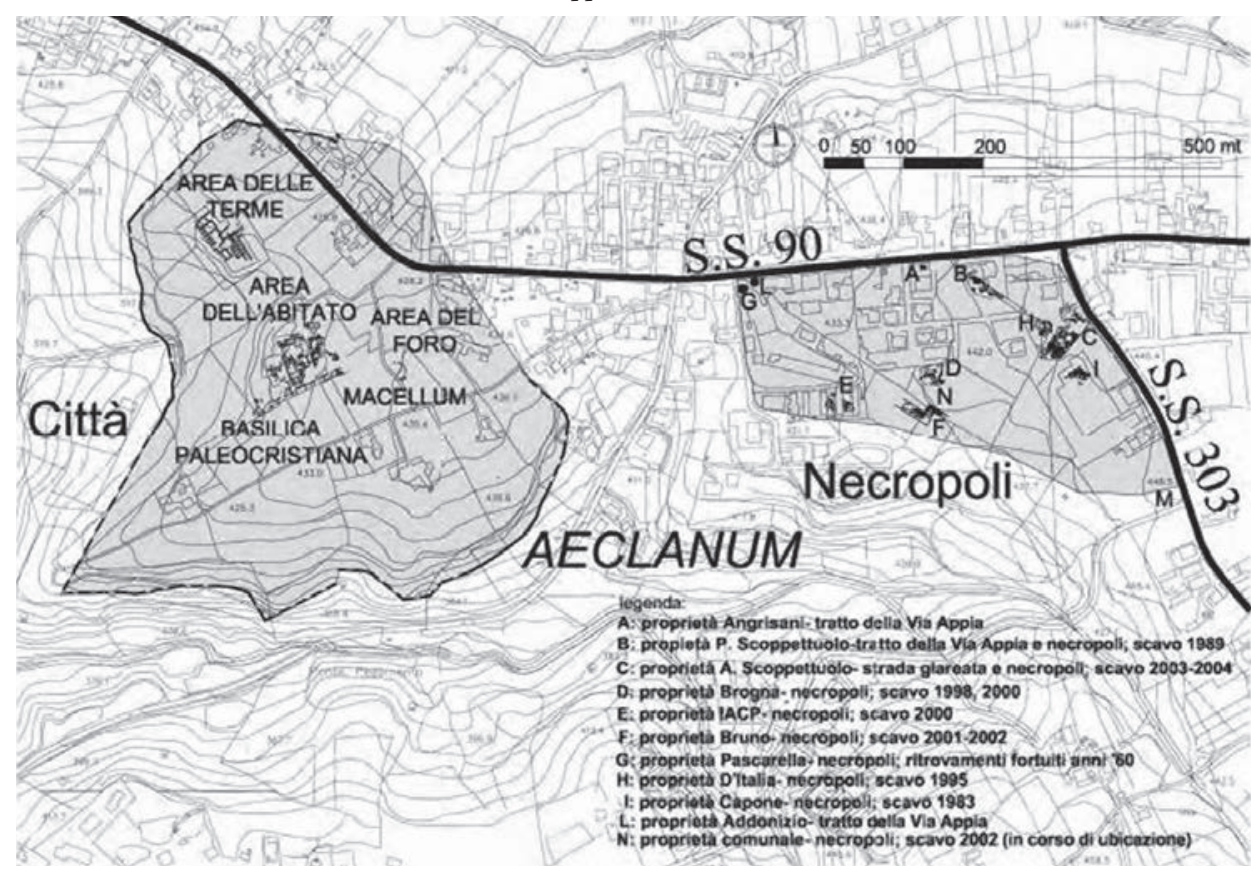

Fig. 16. Aeclanum. Inquadramento aerofotogrammetrico della città e della necropoli. potenziale commemorativo della parola scritta, anche di contenuto cristiano, affidata alla scrittura lapidea: essi dunque non erano privi di un'acculturazione in questo senso tradizionale.

15. I ritrovamenti archeologici inerenti le fasi tardoantiche di Salerno testimoniano, dunque, che gran parte dell'area urbanizzata e dell'immediato suburbio fu coinvolto, in seguito al cospicuo evento alluvionale, in un processo degenerativo che si risolse nell'estinzione, non sempre completa, dell'abitato.

Un'analoga sorte ebbe anche Nola. La città, dove già nel III secolo è attestata raramente la costruzione di nuovi edifici a carattere privato, agli inizi del VI declina per gli effetti dell'alluvione causata dall'eruzione di Pollena'. Già privato da secoli del ruolo di principale riferimento dell'area e parzialmente spopolato, il centro si restringe intorno al foro, mentre i quartieri periferici e i grandi edifici pubblici risultano abbandonati. Si sviluppa solo il santuario martiriale di S. Felice, intorno al quale nella seconda metà del IV viene strutturandosi il vicus christianorum ricordato per la prima volta nel 399-400 da Paolino di Nola ${ }^{80}$.

Oltre agli eventi naturali, nelle città campane si avvertirono soprattutto gli effetti catastrofici della guerra grecogotica. Ad Abellinum (fig. 15), come già precedentemente accennato, il centro aveva preso a svuotarsi dopo il terremoto del 346, con la diaspora della popolazione dal sito murato di pianura (l'attuale Atripalda) nelle nuove sedi impiantate sulla collina detta la Terra e sul mons Truppoaldi ${ }^{81}$ ove fu edificato un castrum distinto dalla civitas (attestato nell'888),

Ad Aeclanum (fig. 16) fu abbandonata solo l'area del foro perché distrutta. La città era situata al centro di un'articolata rete di comunicazioni lungo il tracciato della via Appia. Questa sua posizione geografica le permise di avere un ruolo di primo piano nel Sannio Irpino durante 79 Molte scelte stilistiche operate dai lapicidi furono dovute all'esigenza di compensare la loro scarsa abilità tecnica e non dipesero dalla volontà di aderire
al generale mutamento di gusto e di modalità espressive dell'età tardo antica. Un esempio di queste scelte è l'adozione del solco 'a cordone' che era più
rapido da eseguire, ma molto più irregolare e meno leggibile rispetto all'incisione 'a solco triangolare', tipica dell'epigrafia classica; C. LAMBERT, Salerno.
Le iscrizioni tardoantiche dalla necropoli di via Vicinanza, in Salternum, XIV, nn. 24-25, Salerno, 2010, pp.125-128.
${ }^{80}$ Le origini del vicus vanno individuate nell'impianto di una necropoli nel suburbio settentrionale della città, nell'attuale territorio di Cimitile, e nel suo
incremento dalla seconda metà del III secolo conseguente alla costruzione di mausolei cristiani e alla deposizione del presbitero Felice la cui tomba, per
essere oggetto di venerazione, attrasse nuove sepolture, sicché si verificò una massiccia e disordinata sovrapposizione di inumazioni cristiane in tutti gli
spazi disponibili. Dopo l'esondazione di inizi VI, la vita del complesso martiriale riprese prontamente come dimostra la costruzione, sugli strati alluvionali,
dell'abside occidentale di S. Felice e della basilica di S. Tommaso. Se è vero che il sepolcro di S. Felice influenzò lo sviluppo di Nola, dando luogo ad un
fenomeno di urbanizzazione del suburbio settentrionale, il borgo sorto intorno al santuario rimase un'appendice separata dalla città antica. Su Cimitile
cfr. C. EBANISTA, et manet in mediis quasi gemma intersita tectis. La basilica di S. Felice a Cimitile: storia degli scavi, fasi edilizie, reperti (Memorie dell'Ac-
cademia di Archeologia, Lettere e Belle Arti in Napoli, XV), Napoli, 2003.
${ }^{81}$ G. COLUCCI PESCATORI, L'alta valle del Sabato e la colonia romana diAbellinum, in Annali 1985-86. L'Irpinia nella società meridionale, Avellino, 1987, pp. 139-157. 


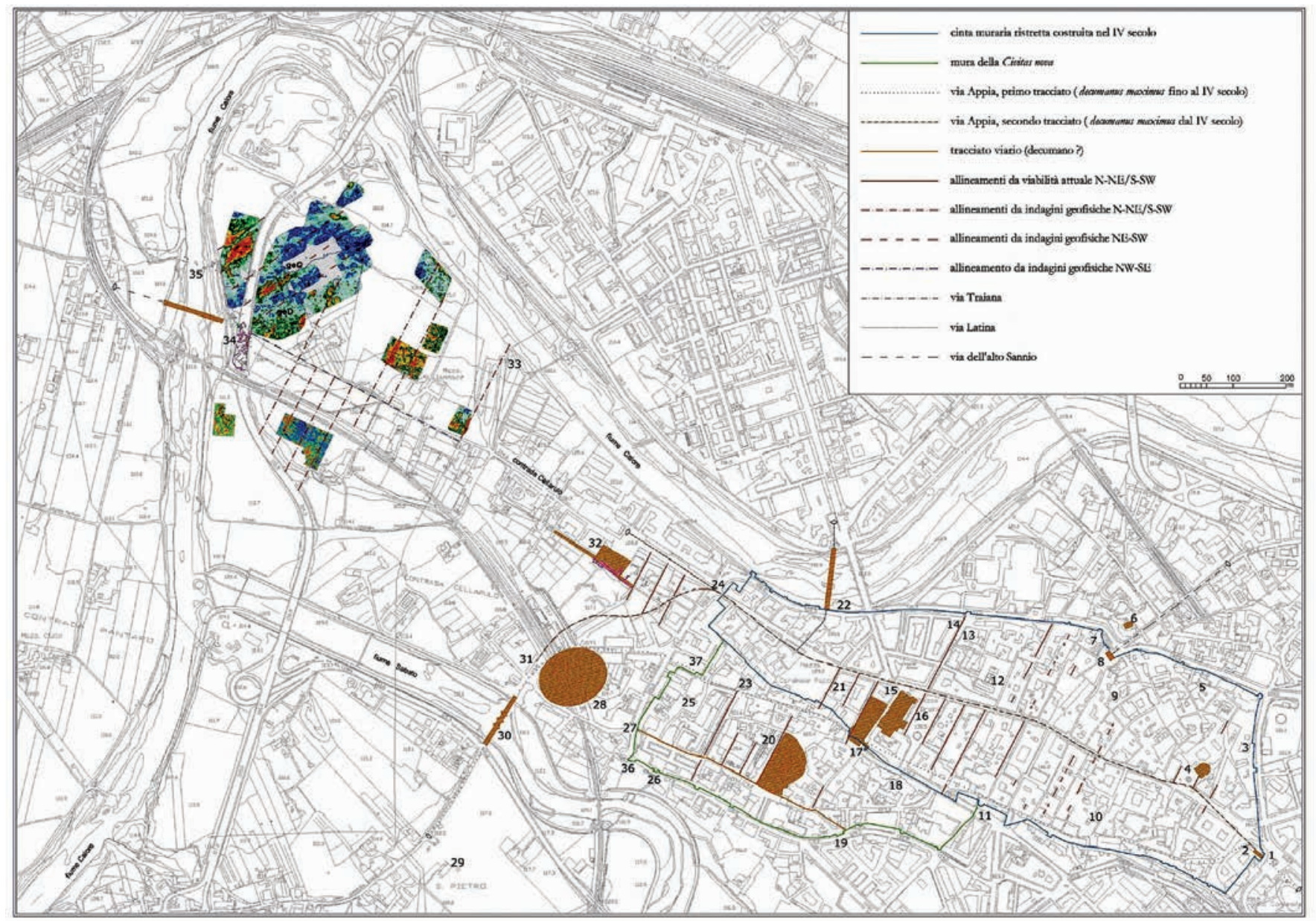

Fig. 17. Benevento e area di Cellarulo, planimetria con restituzione grafica delle indagini geodiagnostiche e ricostruzione della città tardoantica: 1. Porta Somma con fortilizio nella Rocca dei Rettori; 2. Chiesa e monastero di S. Maria di Porta Somma, nei pressi chiesa di S. Giovanni di Porta Somma; 3. Chiesa e Xenodochio di S. Benedetto ad Caballum, nei pressi del «loco Caballo»; 4. Chiesa e monastero di S. Sofia; 5. Chiesa di S. Pietro ad Caballum e nella zona chiesa di S. Angelo de Caballo; 6. Chiesa di S. Ilario a Port'Aurea; nella zona a varie distanze, monastero di S. Sofia a Ponticello, Xenodochio e chiesa di S. Michele Arcangelo "que constructa esse videtur foras hanc cibitate $(m)$ ultra porta $(m)$ Aurea $(m)$, trans ipso ponticello frabito" e chiesa di S. Valentino; 7. Monastero di S. Giovanni a Port'Aurea; 8. Arco di Traiano, Port'Aurea; 9. Chiesa di S. Matteo a Port'Aurea e, nella zona, chiesa di S. Angelo a Port'Aurea; 10. Monastero di S. Vittorino; 11. Porta Rufina; nei pressi trasenda de Olibola, chiese di S. Artellaide e S. Renato, ecclesiae S. Benedicti de adobbatoris detta più tardi de scalellis e S. Nicolay de suburbio, platea puplica vicino alla chiesa di S. Renato; lungo la strada "que descendit ad portam Rufini" monastero di S. Salvatore; 12. Zona delle chiese di S. Mauro e S. Costanzo; 13. Monastero di S. Adeodato; 14. Monastero di S. Paolo, «secus murum huius beneventanae civitatis", "erga trasendam puplicam que dicitur de Leone iudice»; 15. Platea puplica recta; nei pressi casa di Dacomario con torre e pontile e altro pontile; a non grande distanza, quasi certamente nella Civitas nova, chiesa di S. Giovanni de fabricatoribus; 16. Cattedrale e basilica di S. Bartolomeo apostolo de Episcopio; 17. Arco del Sacramento, porta della cinta di IV secolo; 18. Chiesa e monastero di S. Modesto; 19. Porta Nova; nei pressi chiesa di S. Nazzaro de lutifiguli; 20. Teatro, nei pressi monastero dei Ss. Lupulo e Zosimo; vicino trasenda e «platea puplica, qui descendit ad porta que dicitur de Hiscardi»; 21. Ecclesia S. Stephani de monialibus de Foro, nei pressi ecclesia S. Jacobi a Foro e in piazza cardinal Pacca monastero di S. Pietro de monachabus sulle strutture di un edificio forse termale; nei pressi acquedotto romano; 22. Ponte di S. Onofrio; 23. Chiesa dei Ss. Filippo e Giacomo; nei pressi trasenda dei Calderari; chiese di S. Tecla e S. Secondino; 24. Porta S. Lorenzo; nei pressi chiesa e monastero di S. Lorenzo; 25. Edificio termale; nei pressi ecclesia S. Bartholomei in thermis; 26. Torre con arco di porta romana, identificabile con la Turris Pagana; nei pressi ecclesia S. Nicolay Turris Paganae; 27. Port'Arsa-Porta Liscardi; al n. 76 di via Torre della Catena, edificio romano sul cui muro perimetrale è fondato il muro di cinta della Civitas nova; 28. Anfiteatro; 29. Monastero di S. Pietro fuori le mura; 30. Ponte Leproso; 31. Chiesa di S. Cosma; 32. Edificio romano detto «I Santi Quaranta» dal titolo dell'omonima chiesa; 33. Area del porto fluviale; 34 . Quartiere artigianale, area degli scavi archeologici; 35. Pons Maior-Ponte fratto

l'età romana e fino all'alto medioevo. Colonia dall'età adrianea, con la riforma di Diocleziano fu inserita nella provincia Apulia et Calabria; agli inizi del V secolo è attestata come sede di diocesi con il vescovo Giuliano, seguace dell'eresia pelagiana. Dalla seconda metà del VI, il centro, ormai in decadenza, non fu più menzionato nelle fonti documentarie, fatta eccezione di una concessione pontificia degli inizi dell'VIII secolo nel quale venne definito civitas diruta. In età altomedievale, un nuovo abitato (Quintodecimo), strutturato in parte su quello antico, divenne un importante punto di riferimento nell'organizzazione territoriale del ducato di
Benevento. I rinvenimenti archeologici effettuati negli ultimi anni, riferibili ad una necropoli e ad una basilica tardoantica della città nonché alla viabilità romana, hanno apportato elementi fondamentali alla conoscenza del territorio ${ }^{82}$.

16. Quanto è stato richiamato non impedì che si compissero interventi di manutenzione e persino nuove edificazioni pubbliche in alcuni centri di cui è testimoniata la crisi o in alcuni loro settori ${ }^{8}$. A Compsa, riconquistata da Narsete nel 555 e ritornata per un breve periodo sotto il dominio bizantino, alla fine della guerra greco-gotica l'area del foro venne

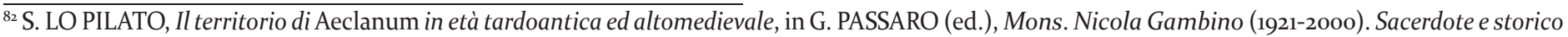
dell'Irpinia el ricordo di amici ed estimatori; atti del convegno di studi, Rocca San Felice, 10 dicembre 2011, Grottaminarda (Av), 2013, pp. 59-96.

${ }_{3}^{8}$ P. DELOGU, op. cit (n. 77), p. 148. 


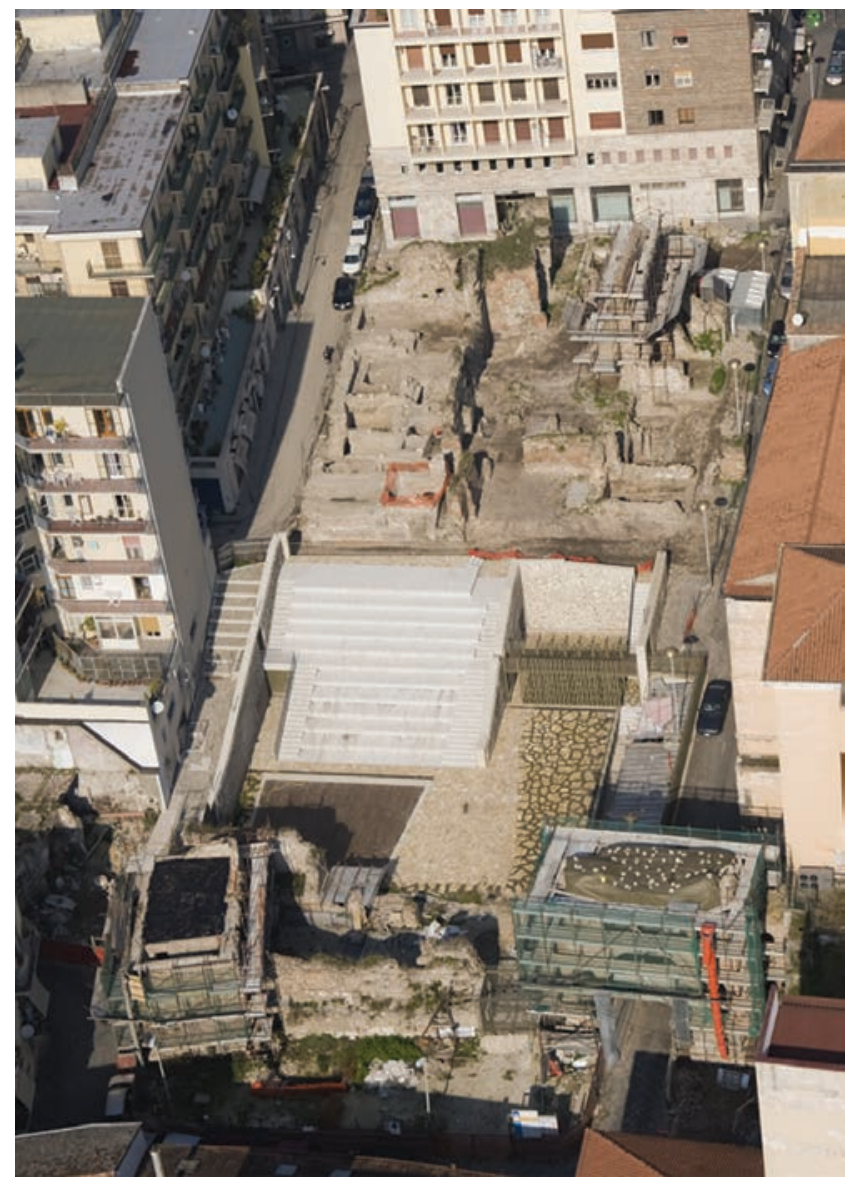

Fig. 18. Area dell'Arco del Sacramento durante i lavori di restauro (2008), Benevento.

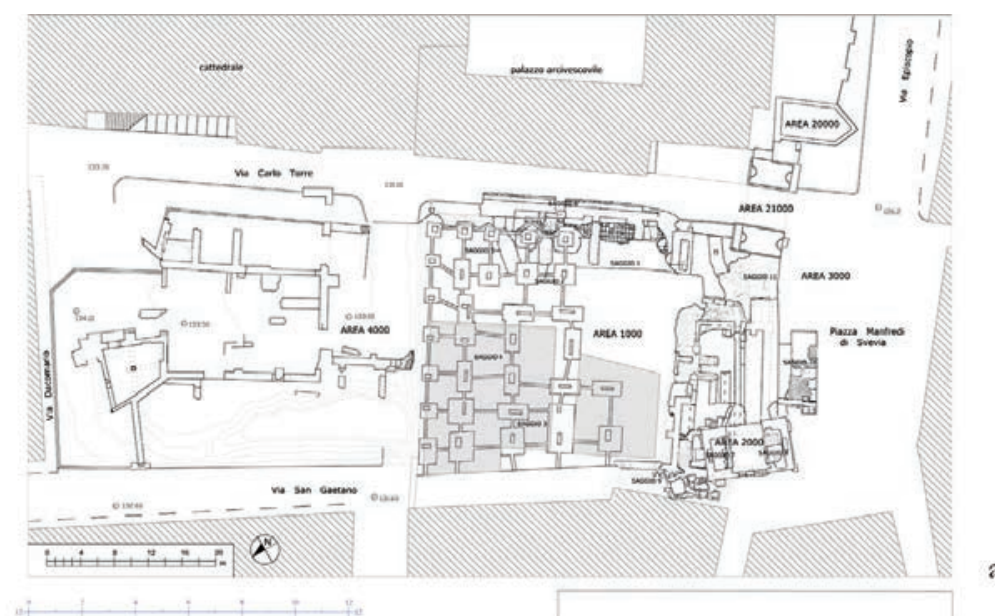

completamente ristrutturata. Inoltre, per controllare la via che univa la città alla variante che da Aeclanum passava per Frigento e per il Formicoso, a metà del VI secolo fu costruito un piccolo borgo fortificato ad Andretta.

Lungo l'Appia rimangono attive solo Capua che, priva di mura dal V secolo, si era andata restringendo e dopo l'istituzione del gastaldato aveva subito un intervento di riorganizzazione urbana ${ }^{84}$ e Benevento. Nella Capua vetus, centro di pianura lungo l'Appia distrutto dai Saraceni nell'841, la tendenza a edificare apparati difensivi si manifesta nella trasformazione dell'anfiteatro in fortezza: il toponimo Berelais, riferito ai giochi praticati nell'arena con gli orsi, si identifica con l'anfiteatro e con la stessa città ${ }^{85}$; alla fine del IX secolo l'anfiteatro-Berelais sarà il castello da cui il longobardo Guaiferio muoverà contro i suoi vicini ${ }^{86}$.

17. A Benevento (fig. 17), snodo di arterie che sarebbero rimaste in funzione per gran parte dell'alto medioevo come
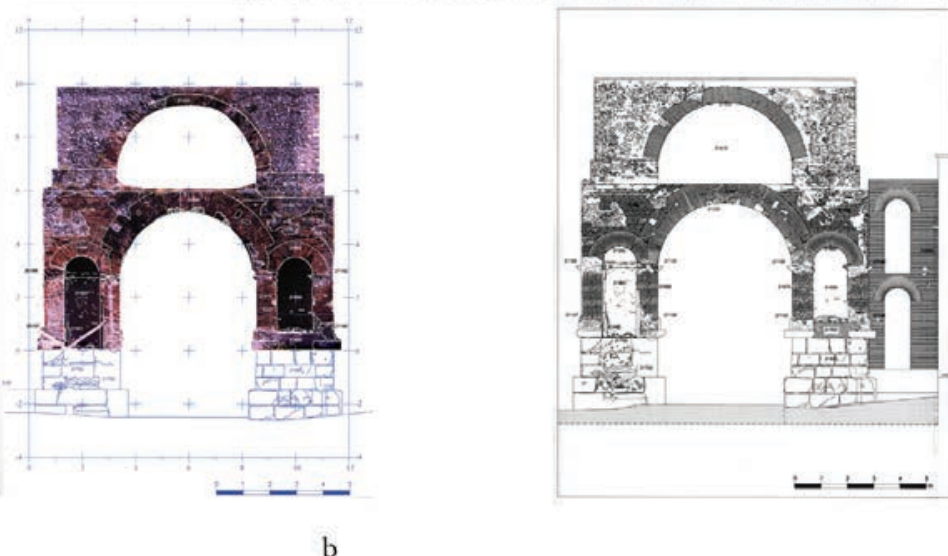

Fig. 19. a - Area dell'Arco del Sacramento, pianta degli scavi, Benevento; $b$ - Rilievo fotogrammetrico dell'Arco del Sacramento; c - Prospetto dell'Arco del Sacramento.

l'Appia e la Traiana, i Longobardi ebbero la necessità di riparare i danni arrecati alle opere di difesa da Totila nel $542^{87}$. A proposito della distruzione delle mura di Spoleto da parte del re ostrogoto, Procopio ne indica il carattere selettivo ${ }^{88}$; è quanto mai probabile che anche la distruzione delle mura di Benevento sia stata parziale e che i Longobardi si siano trovati nella condizione di dover restaurare un impianto già configurato. L'adattamento ad esso sembra evidente nella parte orientale ${ }^{89}$ oltre che nei pressi dell'arco del Sacramento (figg. 18-20, 31) ove il reimpiego della torre pentagonale di IV-V in grossi blocchi di calcare locale ${ }^{90}$ (figg. 19-20; torre che fiancheggia l'antico arco di accesso al foro, divenuto porta urbica $^{91}$ ) indica che il restringimento della città (rispetto alla configurazione di età imperiale cui potrebbe fare riferimento la porta incorporata dalla turris Pagana, nella Civitas nova (fig. 21), restringimento di solito attribuito agli invasori germanici, potrebbe risalire alla ristrutturazione urbana del IV secolo cui fanno riferimento le due epistole che Quinto

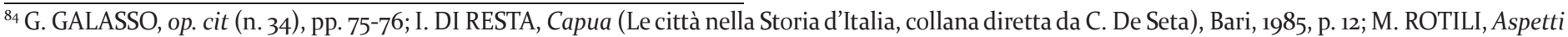
dellinsediamento nel ducato di Benevento, in M. ROTILI (ed.), Memoria del passato, urgenza del futuro. Il mondo romano fra V e VII secolo. Atti delle VI Giornate di studio sull'età romanobarbarica, Benevento 18-20 giugno 1998, Napoli, 1999, pp. 225-243, a p. 236.

${ }^{85}$ N. CILENTO, op. cit. (52), pp. 89, 98, 121, 128, 155 .

${ }^{86}$ V. VON FALKENHAUSEN, op. cit. (n. 53), p. 298.

${ }^{87}$ La guerra gotica, III, 6 (La guerra gotica = La guerra gotica di Procopio di Cesarea, D. COMPARETTI (ed.), Roma, 1895-98, rist. anastatica Bottega d'Erasmo, Torino, 1968-70); M. ROTILI, op cit. (n. 84), p. 233.

${ }^{88}$ La guerra gotica, IV, 33, op. cit. (n. 87); M. ROTILI, Benevento romana e longobarda. L'immagine urbana, Napoli-Ercolano, 1986, p. 87.

${ }^{89} \mathrm{M}$. ROTILI, Benevento e il suo territorio, in I Longobardi dei ducati di Spoleto e Benevento. Atti del XVI Congresso Internazionale di studi sull'alto medioevo, Spoleto, Centro Italiano di Studi sull'alto medioevo, 20-23 ottobre 2002- Benevento, 24-27 ottobre 2002, Spoleto, 2003, pp. 827-879, a pp. 865-866.

${ }^{90}$ Ibidem, p. 864.

${ }^{91}$ M. ROTILI, op cit. (n. 84), p. 239.

${ }_{92}$ Cronologia et prosopographia Symmachiana, in O. SEEK (ed.), op. cit. (n. 6), p. LXXIV. 
Aurelio Simmaco ${ }^{92}$, reduce dall'Africa dov'era stato proconsole, inviava al padre nell'autunno del 375 da Benevento ${ }^{93}$ : esse indicano l'impegno della cittadinanza nel porre riparo ai danni del terremoto del 346; al ripristino (in altra circostanza) di monumenti «ac totius prope civitatis post hostile incendium» fa invece riferimento l'iscrizione mutila ${ }^{94}$ che, alla base della statua a lui dedicata, menzionava l'ignoto autore dei restauri ${ }^{55}$ come conditor (appunto totius prope civitatis post hostile incendium). La costruzione della 'cinta ristretta' (figg. 22-24), tipica della tarda antichità, è speculare all'abbandono di Cellarulo (figg. 25-26) ove recenti indagi$\mathrm{ni}^{96}$ hanno rivelato che la frequentazione sistematica dell'area cessa nel IV-V secolo, contestualmente, appunto, all'arroccamento difensivo sul colle della Guardia che comportò almeno il dimezzamento del centro97.

La costruzione delle mura ${ }^{98}$ comportò lo spoglio dell'anfiteatro come indica il riuso di rilievi di soggetto gladiatorio e di grandi blocchi ${ }^{99}$ : già abbandonato nel IV secolo ${ }^{100}$, esso venne rasato anche per evitarne l'impiego da parte di eventuali aggressori quale base d'attacco contro la città. Viceversa il teatro (figg. 27-28), prossimo all'area urbanizzata tanto che nell'VIII secolo verrà a trovarsi all'interno della Civitas nova $a^{101}$ promossa da Arechi II, venne reimpiegato per scopi abitativi.

Alle ristrutturazioni promosse dall'aristocrazia beneventana lodata da Simmaco per l'impegno posto nel rinnovare la città può essere attribuita la costruzione della chiesa madre sorta su due insulae, nei pressi dell'arco del Sacramento, dopo l'editto costantiniano se non fra IV e V secolo, con l'impianto basilicale proprio delle grandi chiese paleocristiane: le 56 colonne uguali in essa reimpiegate (figg. 29-30) con relative basi e capitelli ${ }^{102}$ non possono essere state prelevate da un monumento antico (forse il teatro o l'anfiteatro) se non tutte insieme, quando l'assetto complessivo di questo le rendeva ancora disponibili, cosa che non sarebbe stata possibile in età altomedievale come dimostra la disuguaglianza fra le 8 colonne di reimpiego,
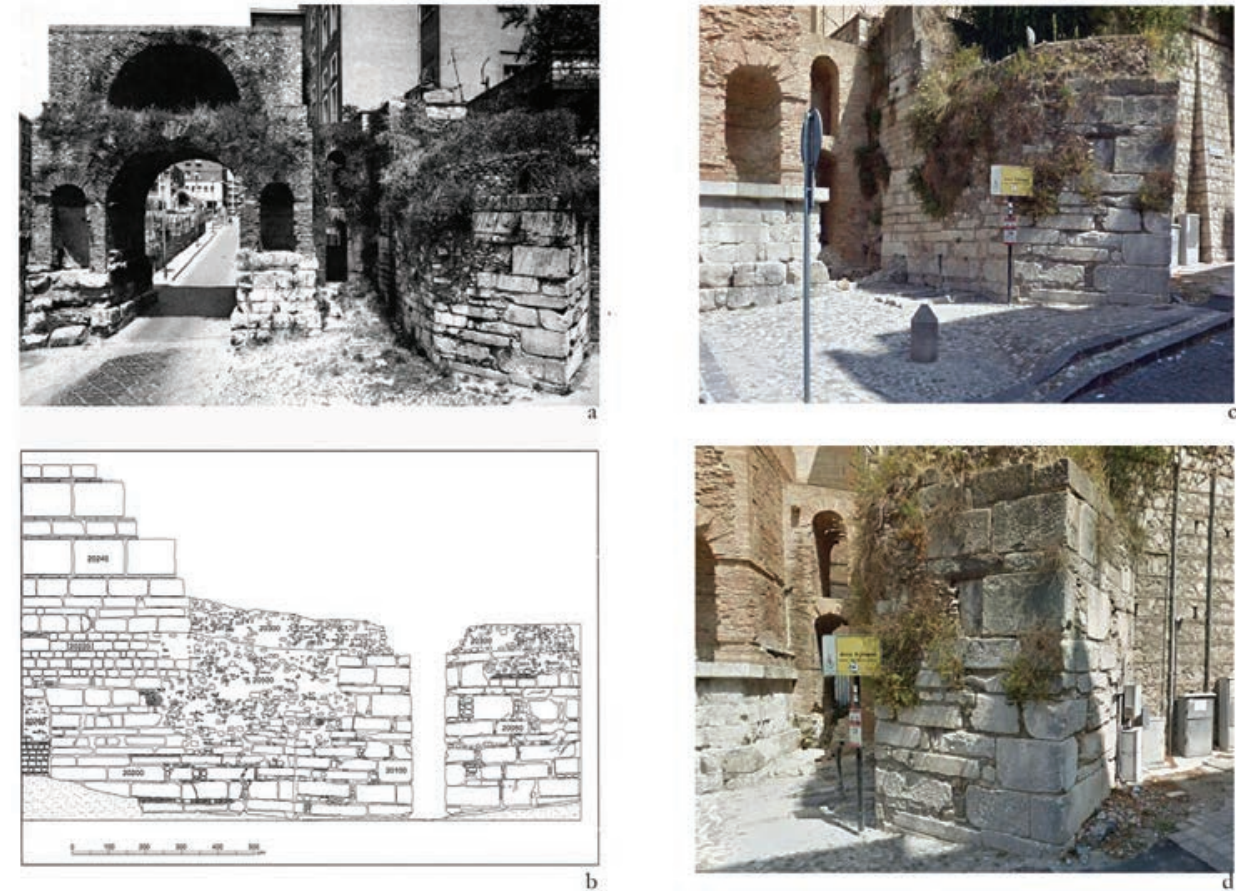

Fig. 20. a-Benevento, Arco del Sacramento e torre pentagonale nel circuito murario del IV secolo; $b, c, d-$ Prospetto e particolari della torre a sezione pentagonale del $V$ secolo.
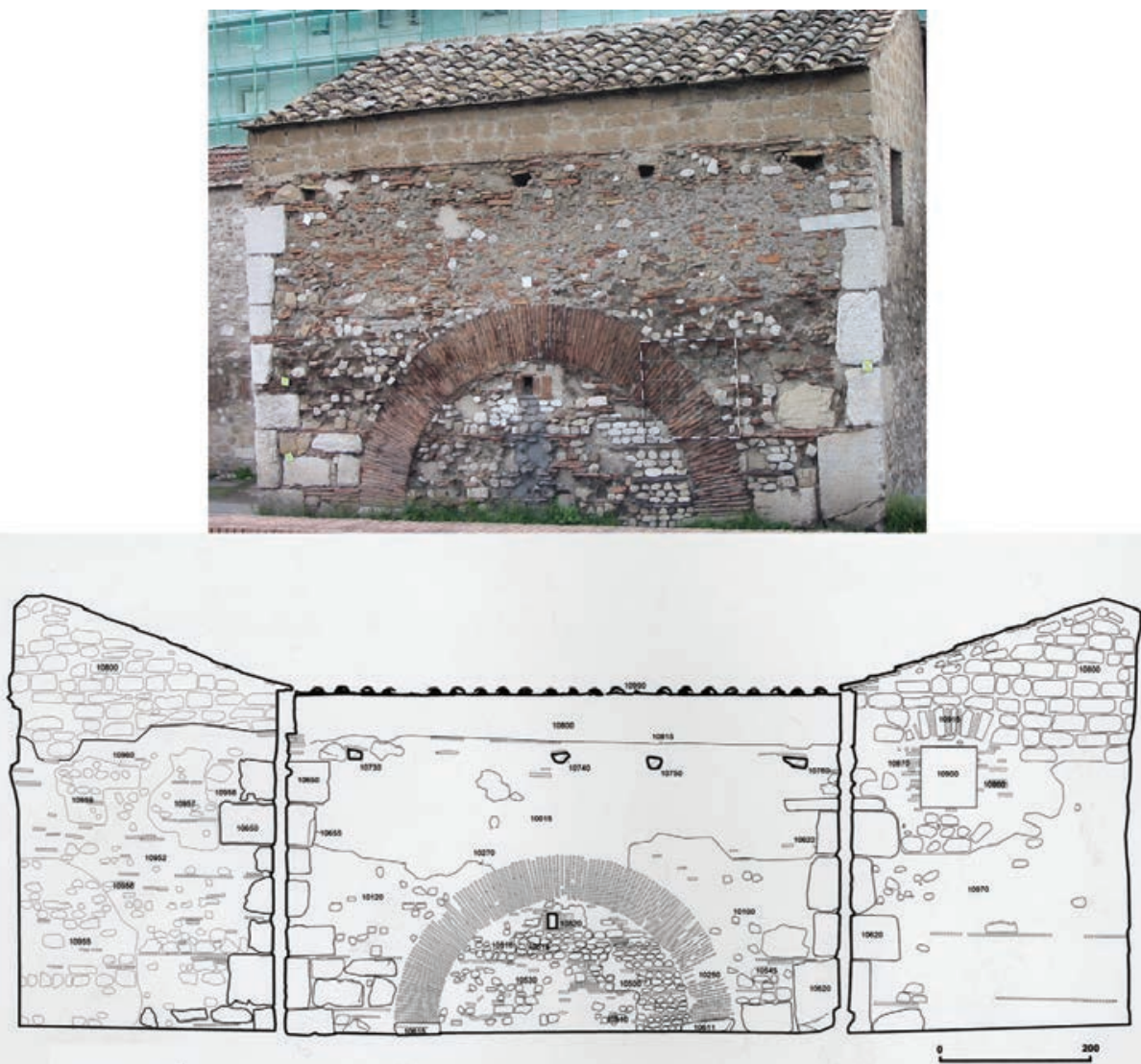

Fig. 21. Benevento, turris Pagana con i resti della porta romana o tardoantica.

${ }_{93}$ SYMMACHI Epistulae, III, a. 375, op. cit. (n. 6), pp. 4-5.

${ }_{94}$ Cfr. M. ROTILI, op cit. (n. 89), p. 865, note 176-178.

95 I lavori di ripristino riguardarono il foro, la basilica e il portico dei Sagittari nella Regio viae novae, le terme commodiane, taluni collegi, il portico di Diana e la basilica di Longino.

${ }_{96}^{6}$ Ricerche di superficie e indagini geofisiche hanno costituito la diagnostica preliminare alla progettazione del Parco archeologico-naturalistico di Cellarulo che il Comune di Benevento ha affidato, per la parte archeologica, al Dipartimento di studio delle componenti culturali del territorio della Seconda Università di Napoli. Le prospezioni geoelettriche, geomagnetiche e georadar sono state eseguite dall'I.T.A.B.C. (Istituto per le tecnologie applicate ai beni culturali) del C.N.R., sotto il coordinamento del prof. Paolo Mauriello.

${ }^{97}$ M. ROTILI, op. cit. (n. 88), pp. 86-87.

${ }_{98}^{8}$ ID., op. cit. (n. 89), pp. 868-870. 

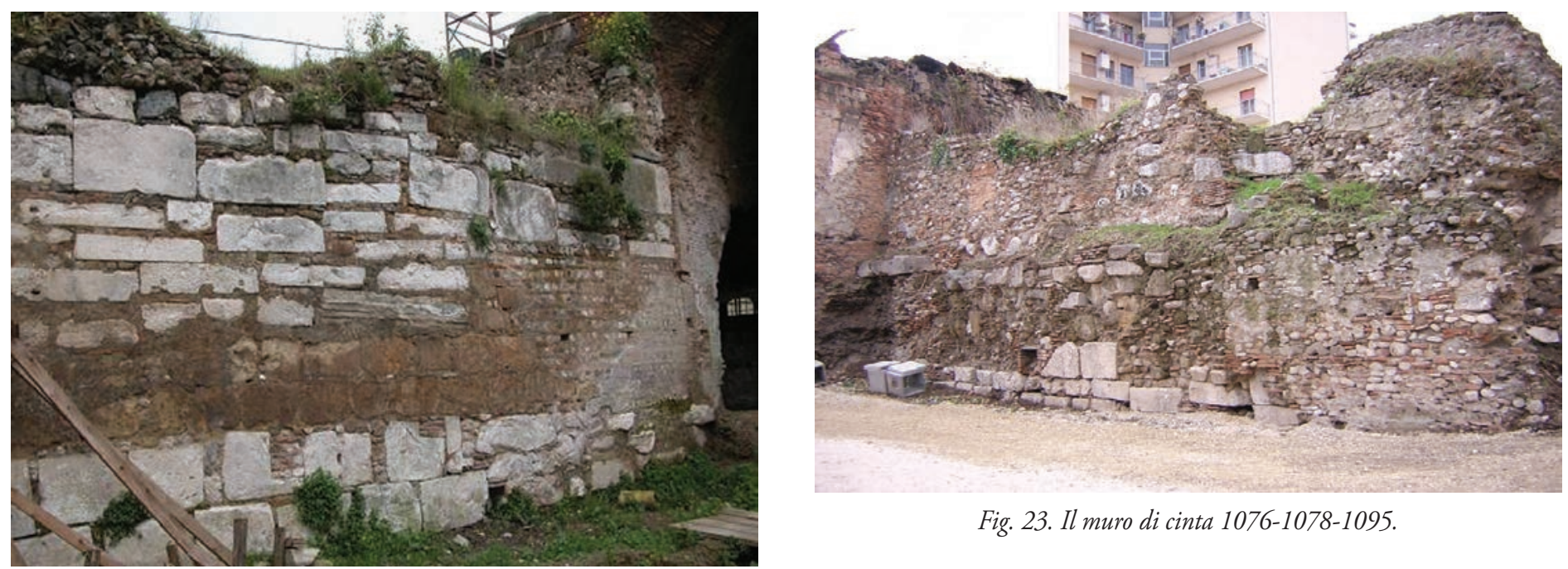

Fig. 23. Il muro di cinta 1076-1078-1095.

Fig. 22. Muro di cinta 1074-1075-1171-1179.

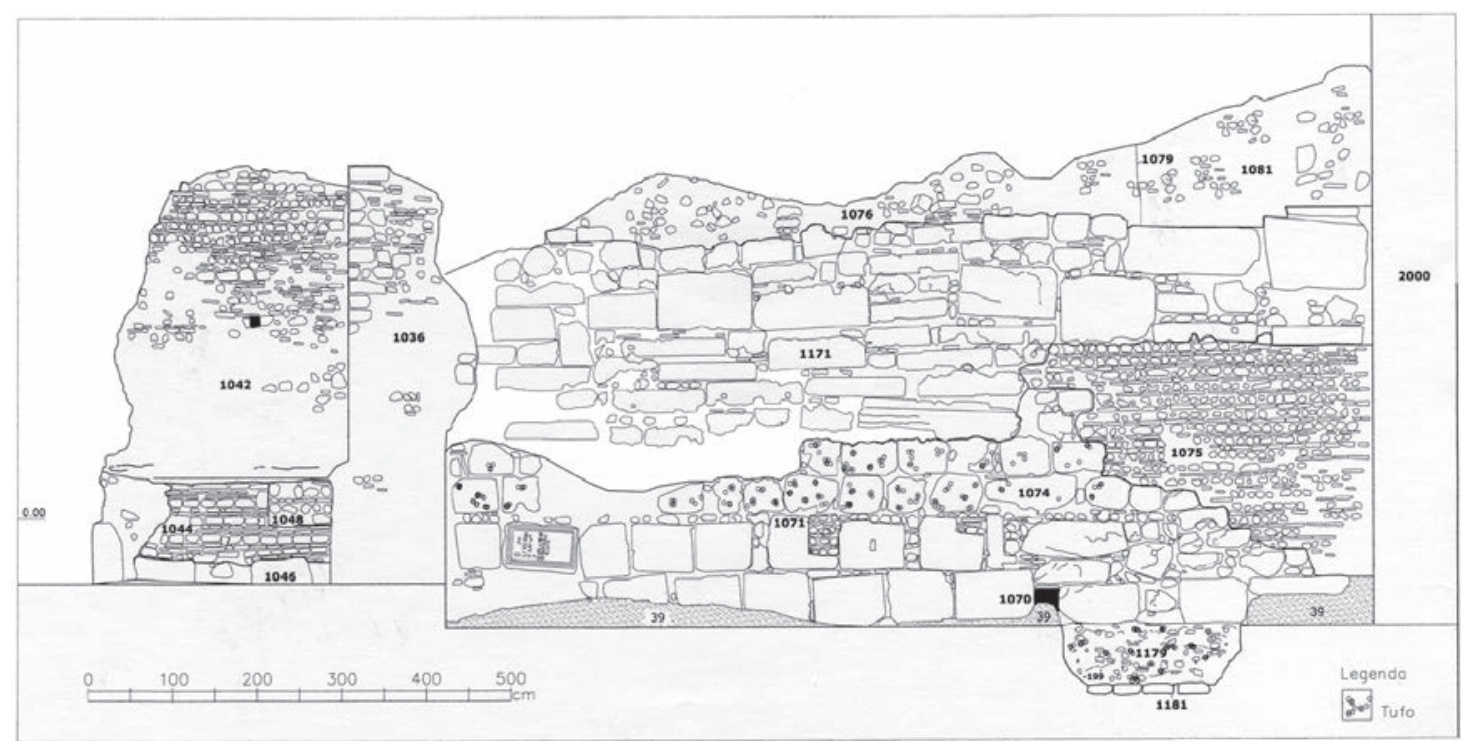

Fig. 24. Rilievo del muro di cinta 1074-1075-1171-1179.

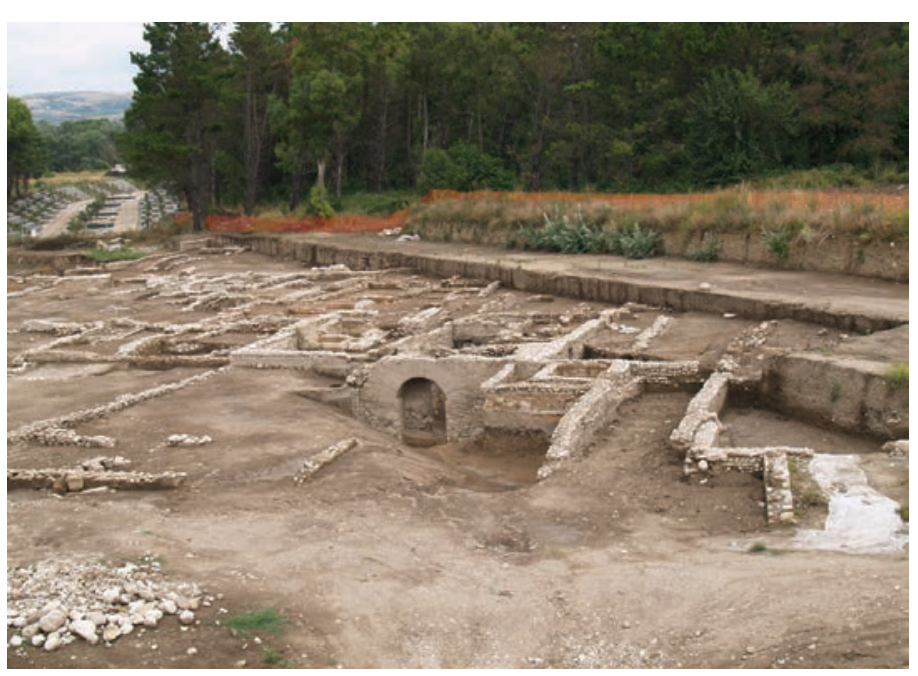

Fig. 25. Benevento, scavi archeologici in contrada Cellarulo.

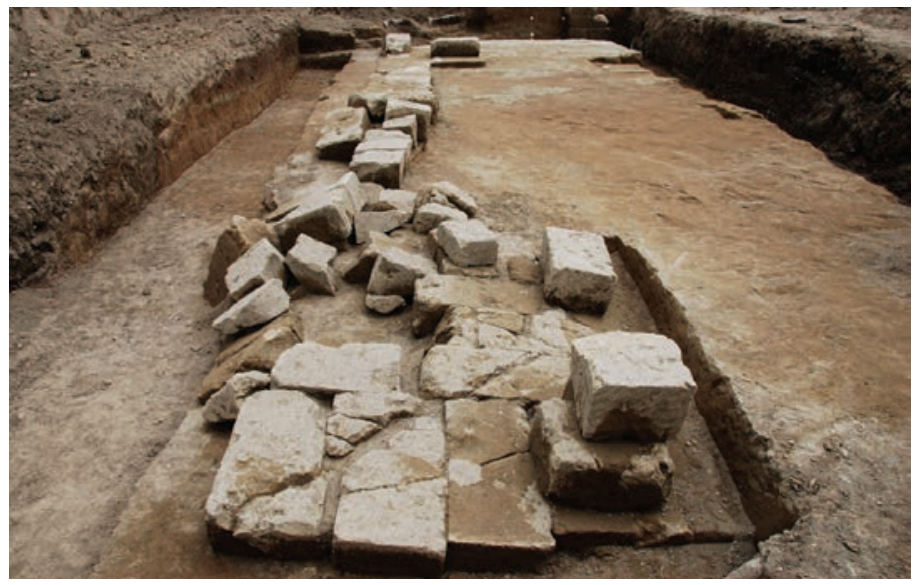

Fig. 26. Muro di cinta e torre a pianta quadrangolare in opera quadrata in blocchi di tufo (III a. C.).

99 ID., op. cit. (n. 88), pp. 55-57.

${ }^{100} \mathrm{G}$. BISOGNO, Intervento alla Tavola rotonda sul tema "Popoli e culture fra Tarda Antichità e Alto Medioevo. Stato della ricerca, prospettive storiografiche e metodologiche", resoconto a cura di M. PUCCI, in M. ROTILI (ed.), Società multiculturali nei secoli V-IX. Scontri, convivenza, integrazione nel Mediterraneo occidentale. Atti delle VII Giornate di studio sull'età romanobarbarica, Benevento 31 maggio-2 giugno 1999, Napoli 2001, pp. 352-361, a pp. 355-356.

${ }^{101}$ M. ROTILI, op. cit. (n. 88), pp. 143-155, 231 nota 283; ID., op. cit. (n. 89), pp. 870-871.

${ }^{102}$ P. PENSABENE, Contributo per una ricerca sul reimpiego e il "recupero" dell'antico nel Medioevo. Il reimpiego nell'architettura normanna con appendice di S. LORENZATTI, in Rivista dell'Istituto Nazionale d'Archeologia e Storia dell'Arte, s. III, XIII (1990), pp. 5-138, a pp. 107-109. 

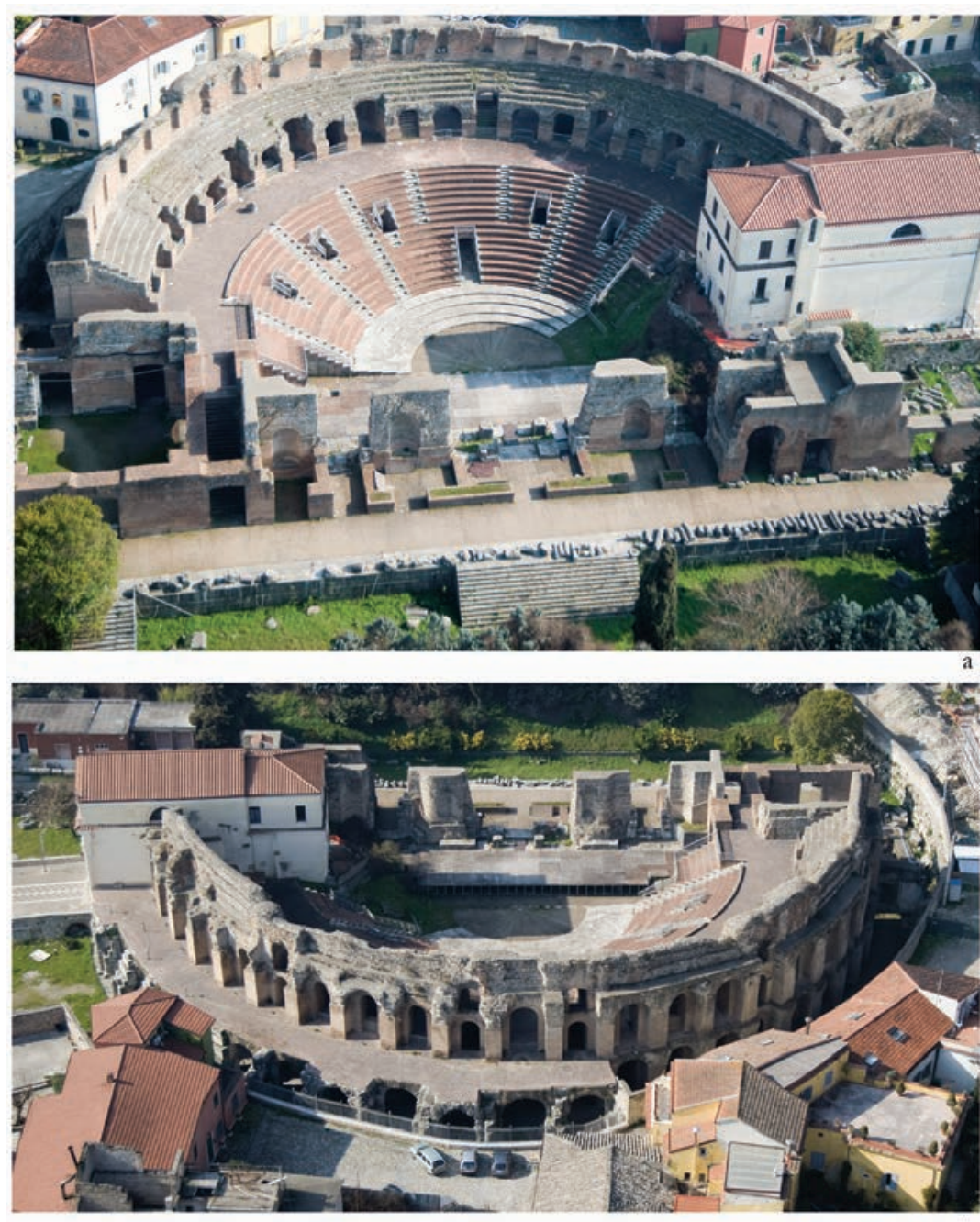

Fig. 27. $a, b$ - Teatro romano, Benevento.

i capitelli e le basi (in realtà capitelli rilavorati per adattarli al diverso scopo funzionale) della chiesa di S. Sofia di Benevento, fondata da Arechi II nel $758^{103}$. Del resto i primi vescovi certi si registrano proprio a partire dal 313: Teofilo

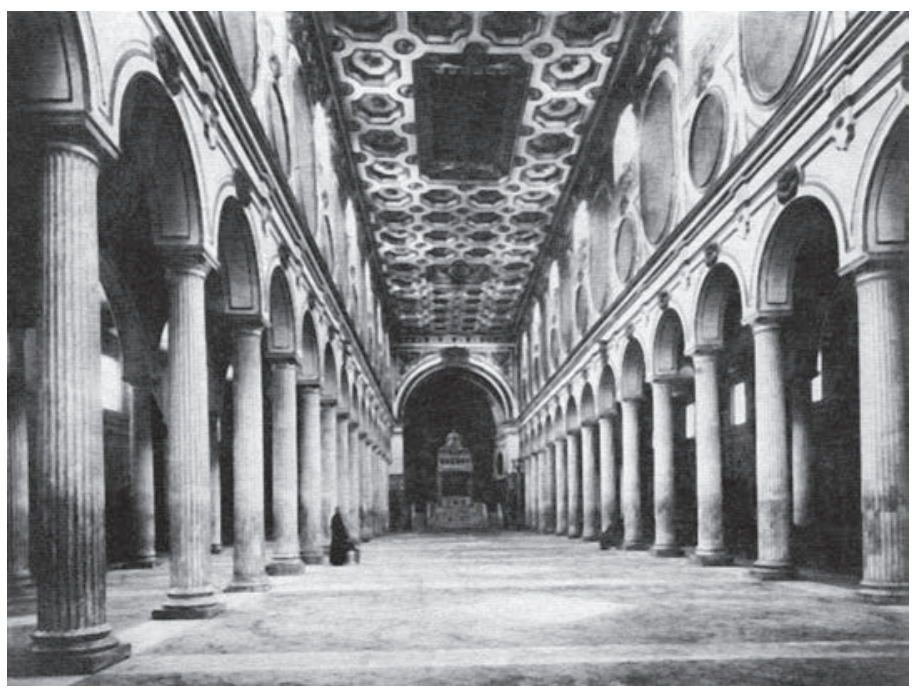

Fig. 29. Benevento, Duomo. Interno, navata centrale.

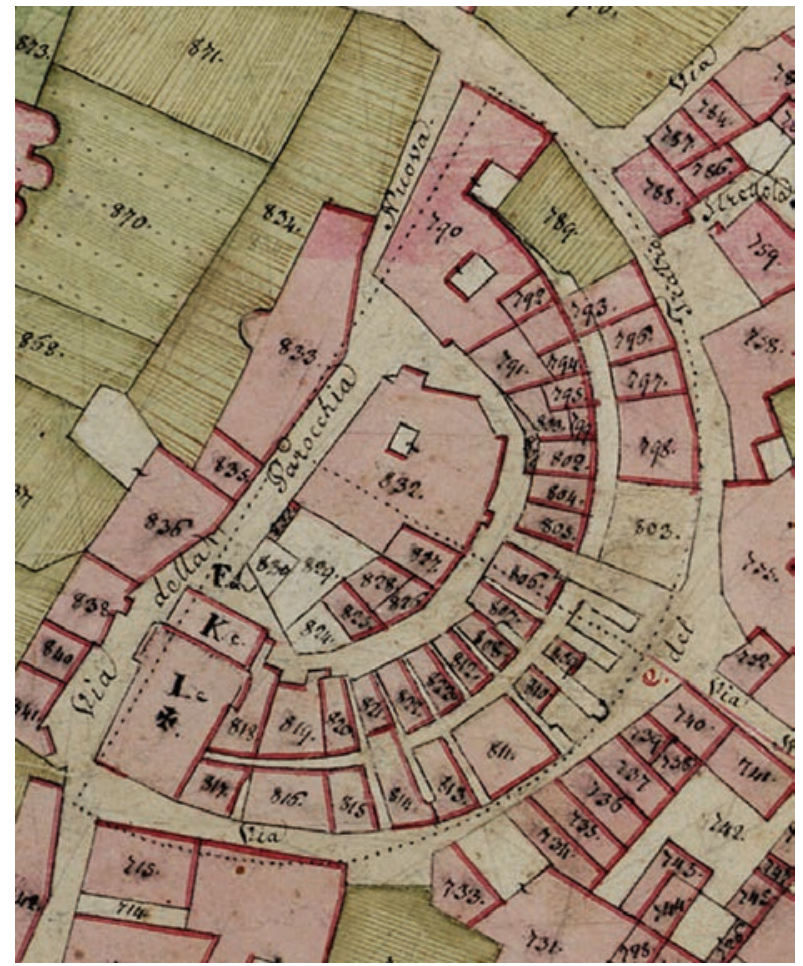

Fig. 28. Luigi Mazarini, Mappa originale della città di Benevento, Roma Archivio di Stato, CPG, 277 n. 1, particolare del teatro.

che partecipa ad una sinodo romana in quell'anno, Gennaro II presente al concilio di Sardica del 34344, Emiliano/Emilio che è legato di Innocenzo I a Costantinopoli nel 406, Doro al quale è indirizzata un'epistola di papa Leone I del 448 ed Epifanio, destinatario di tre missive di papa Gelasio I fra il 494 e il $496^{104}$. Dopo quest'anno la serie si interrompe e riprenderà solo con S. Barbato all'indomani della fallita spedizione di Costante II contro la città nel 663, dell'abbattimento del noce sacro a Wotan e della conversione al cristianesimo dei Longobardi ${ }^{105}$. Restaurata nell'ultimo quarto dell'VIII secolo, la cattedrale fu nuovamente consacrata dal vescovo Davide, contemporaneo

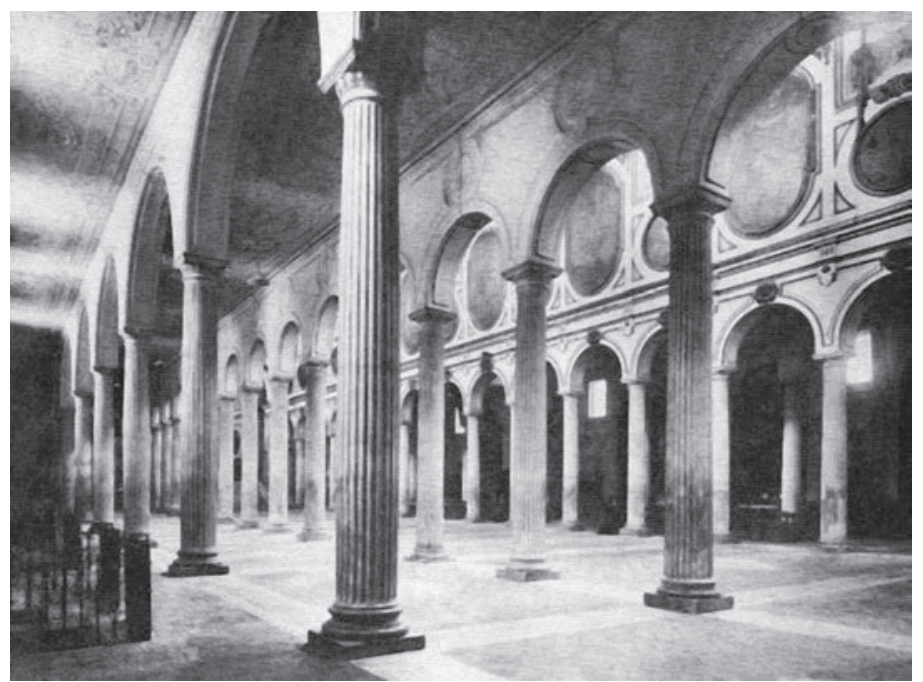

Fig. 30. Benevento, Duomo. Navata centrale e prima navata sinistra

${ }_{103}^{10}$ M. ROTILI, op. cit. (n. 88), pp. 107-109, 143-155, 184-201; ID., op. cit. (n. 89), pp. 861-864.

104 P. F. KEHR, Italia Pontificia, Regesta Pontificum Romanorum. IX. Samnium, Apulia, Lucania, W. HOLTZMANN (ed.), Berlin, 1962, pp. 105-106.

${ }^{105}$ A. PRATESI, Barbato, santo, in Dizionario biografico degli italiani, VI, Roma, 1964, pp. 128-130; M. ROTILI, op. cit. (n. 88), pp. 171-175. Sui problemi della cristianizzazione dei longobardi cfr. M. ROTILI, Forme di cristianizzazione dei Longobardi, in Umbria Cristiana. Dalla diffusione del culto al culto dei santi 


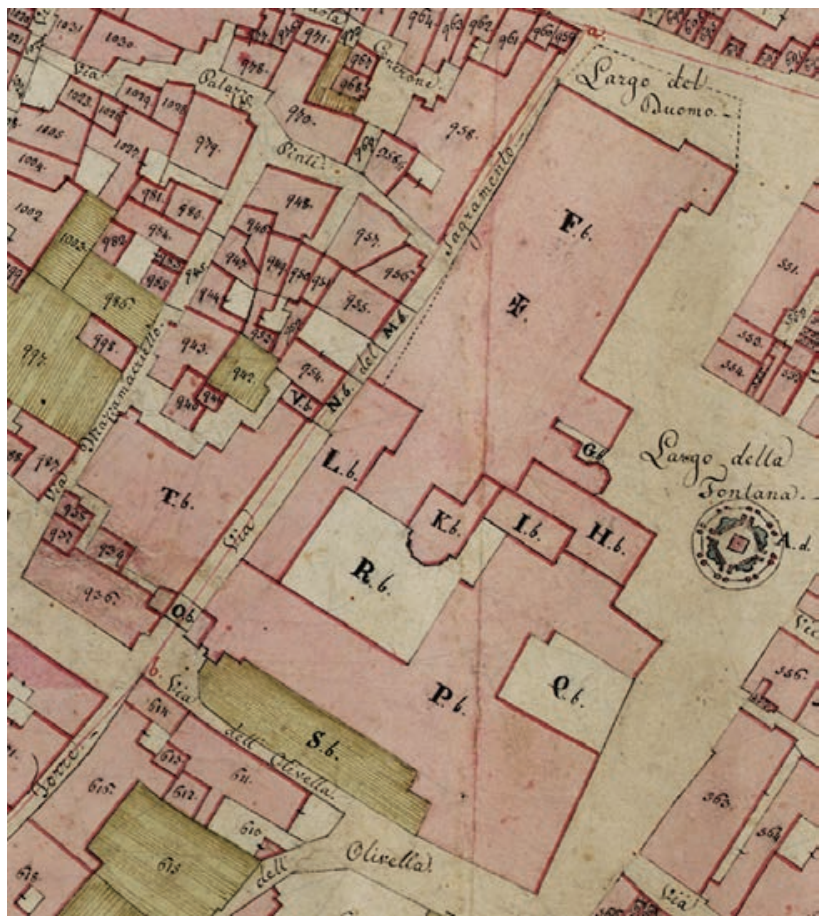

Fig. 31. Luigi Mazarini, Mappa originale della città di Benevento, Roma Archivio di Stato, CPG, 277 N. 1, particolare della cattedrale e dell'area dell'Arco del Sacramento.

di Arechi II: ai lavori allora condotti vanno sommati quelli effettuati al tempo di Sicone ${ }^{106}$, ma l'impianto paleocristiano e tardoantico dell'originaria chiesa a 3 navate con pronao venne modificato nel XII secolo (figg. 32-33) allorché l'edificio fu strutturato su 5 navate e accorciato, attuando in forme romaniche una redistribuzione dei materiali da costruzione oltre che degli spazi.

\section{CONCLUSIONI}

Lo studio ha dimostrato che la Campania nel passaggio dalla tarda antichità al medioevo attraversò un lungo e complesso processo di trasformazione del proprio assetto che riguardò in modo molto significativo le città. Il periodo non fu segnato solo dalla scomparsa e dal ridimensionamento di alcune città, ma soprattutto dalla reattività della società che, nonostante fosse vessata da crisi economica, guerre, catastrofi naturali, calo demografico, fu capace di riorganizzare lo spazio urbano sotto la spinta delle immanenti esigenze di difesa (con la costruzione di mura) e dei nuovi elementi di aggregazione territoriale quali furono le sepolture dei santi e le nuove chiese vescovili. Tra il IV e il V secolo nelle città più importanti tornò in auge l'evergetismo (praticato raramente da benefattori locali facoltosi a causa delle condizioni critiche in cui comunque si trovavano le élites municipali) che finanziò interventi indirizzati al recupero e alla manutenzione delle infrastrutture antiche. Dal V secolo il processo di destrutturazione urbana si concretizzò nella creazione di spazi verdi destinati a orti e pascoli e di depositi la cui consistenza fu frutto del collasso del sistema fognario e del diffuso accumulo di rifiuti (anche

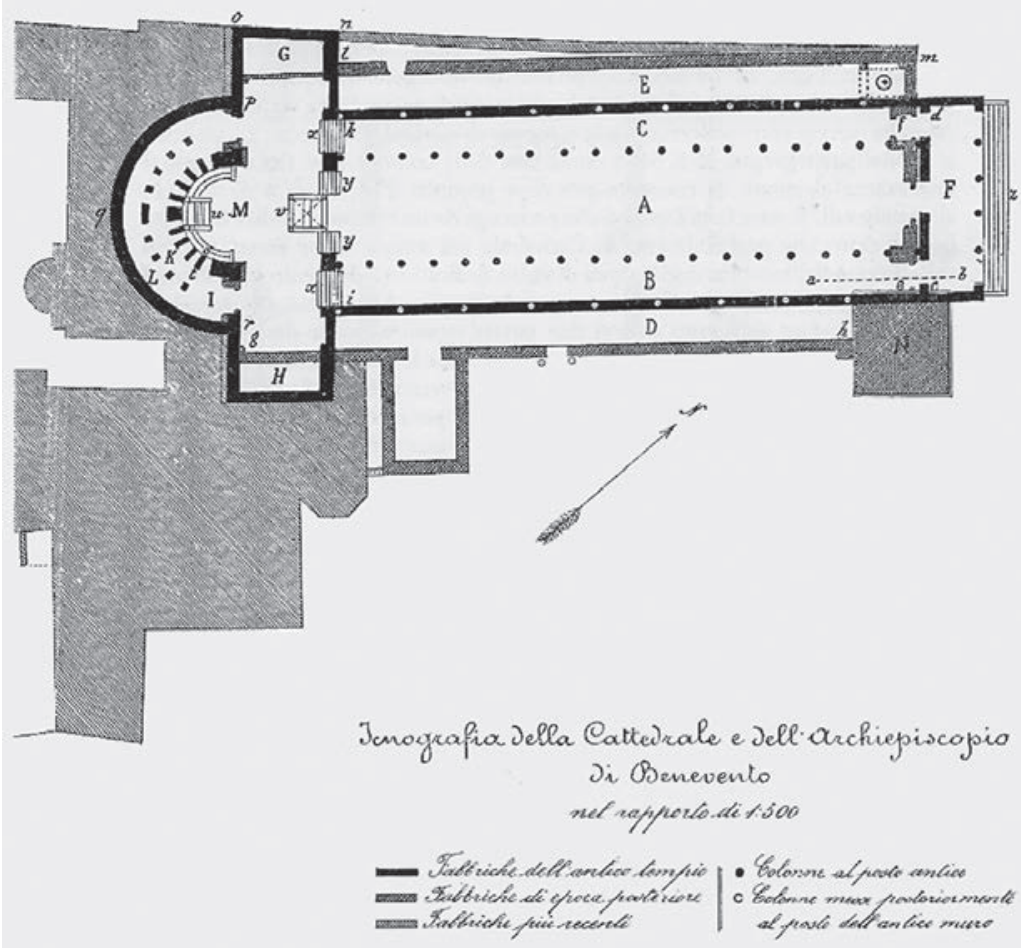

Fig. 32. Benevento, pianta della cattedrale di XII-XIII. Ricostruzione della planimetria dell'edificio paleocristiano pubblicata da A. Meomartini nel 1889-95.

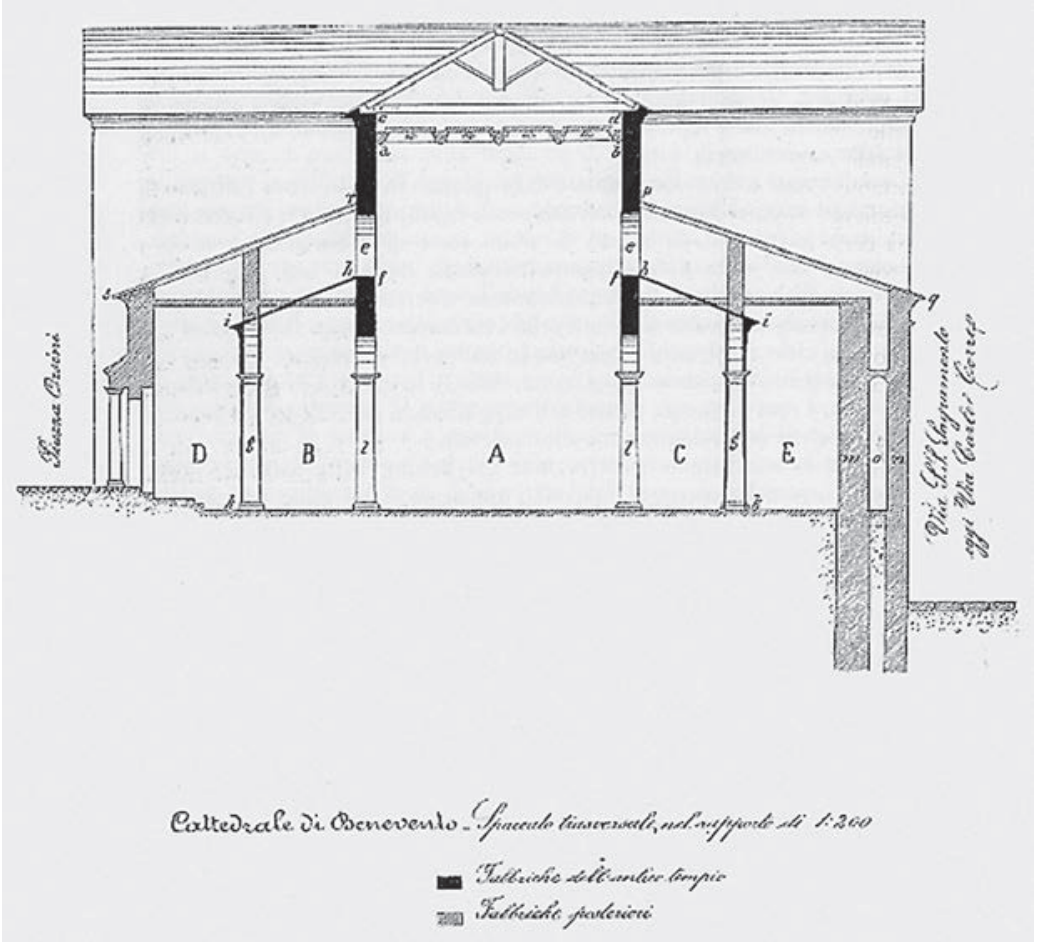

Fig. 33. Benevento, sezione della cattedrale di XII-XIII. Ricostruzione della sezione trasversale dell'edificio paleocristiano pubblicata da A. Meomartini nel 1889-95.

a forte componente organica), come si è registrato nelle indagini archeologiche condotte a Napoli. Un altro aspetto della destrutturazione fu la distribuzione diffusa dei nuclei sepolcrali all'interno del perimetro cittadino.

Contribuirono alla decadenza delle città anche fenomeni catastrofici quali terremoti (Benevento fu colpita da un

(secc. IV-X), in Atti del XV Congresso Internazionale di studi sull'alto medioevo, Spoleto, Centro Italiano di Studi sull'alto medioevo, 23-28 ottobre 20oo, Spoleto, 2001, pp. 223-256.

${ }^{106}$ M. ROTILI, op. cit. (n. 88), pp. 178-180. 
gravissimo sisma nel 346 mentre meno probabile appare quello del 375), alluvioni (testimoniate a Salerno e a Nola dal rinvenimento di strati e detriti alluvionali negli scavi archeologici), fenomeni vulcanici (il bradisismo dell'area dei campi flegrei e l'eruzione detta di 'Pollena'); l'avanzamento della linea di costa produsse, come si èvisto, l’insabbiamento dell'antico porto di Napoli. Mentre si assisteva al ridimensionamento delle città più importanti, sorsero centri, di solito piccoli e di scarso rilievo che costituirono le maglie dell'organizzazione amministrativa ed ecclesiastica: essi se riuscirono a resistere alla guerra goto-bizantina alla fine del VI non ressero ai fattori di recessione menzionati e all'occupazione del territorio conseguente alla conquista dei Longobardi. Nel Mezzogiorno la presenza di questi ultimi, da qualcuno ritenuta incruenta, fu certamente inferiore e diversa rispetto a quella registrata nel Norditalia dalle numerose necropoli 'familiari' riferibili alle farae che attuarono la conquista; ciò nonostante essa accentuò comunque il collasso della produzione agricola e della vita cittadina. Pertanto anche in Campania l'età longobarda si connotò come il momento finale della destrutturazione dell'organizzazione urbana avviata nella tarda età romana.

\footnotetext{
* Referenze delle illustrazioni: Figg 1-3, (F. SIRANO, op. cit. (n. 2), figg. 5 p.138, 6 p. 140, 8 p. 143); Figg. 4-5, 7 ( P. A. GIANFROTTA, op. cit. (n. 7), figg. 2-3 p. 16, 5 p. 22, 4 p. 17); Fig. 6 (B. ANDREAE, Il ninfeo di Punta dell'Epitaffio a Baia, in S. S. TUCCHI, M. BONANNO, A. RAVANTINOS (eds.), Giornate di studio in onore di Achille Adriani (Roma 26-27 novembre 1984), Roma, 1991, pp. 237-265); Fig. 8 (elaborazione grafica NEW ARCHAEOLOGY, 2005); Fig. 9 (P. ARTHUR, op. cit. (n. 2), fig. 1); Figg. 10-13 (D. GIAMPAOLA, V. CARSANA, op. cit. (n. 71), figg. 1 p. 286, 3 p. 288, 4 p. 289, 5 p. 292, 12 p. 300 ); Fig. 14 (C. LAMBERT, op. cit. (n. 79), figg. 1 p. 125, 2-3 p. 126); Fig. 15 (Elaborazione grafica dell'arch. M.M. COLUCCI); Fig. 16 (S. LO PILATO, op. cit. (n. 82), fig. 1 p. 83); Figg. 17-27 (Archivio ROTILI); Figg. 28, 31 (ARCHIVIO DI STATO DI ROMA, concessione a pubblicare del Ministero per i Beni e le attività culturali, ASR n. 13/2006); Figg. 29-30 (A. MEOMARTINI, Benevento, Istituto Italiano di Arti Grafiche, Bergamo, 1909, p. 52); Figg. 32-33 (A. MEOMARTINI, I monumenti e le opere d'arte della città di Benevento [...], Benevento, 1889-95, Tavv. LVI, LVIII).
} 